\title{
Domestication Explains Two-Thirds of Differential-Gene- Expression Variance between Domestic and Wild Animals; The Remaining One-Third Reflects Intraspecific and Interspecific Variation
}

\author{
Irina Chadaeva (D), Petr Ponomarenko, Rimma Kozhemyakina, Valentin Suslov, Anton Bogomolov, \\ Natalya Klimova, Svetlana Shikhevich, Ludmila Savinkova, Dmitry Oshchepkov, Nikolay A. Kolchanov, \\ Arcady Markel and Mikhail Ponomarenko *D
}

Citation: Chadaeva, I.;

Ponomarenko, P.; Kozhemyakina, R.; Suslov, V.; Bogomolov, A.; Klimova,

N.; Shikhevich, S.; Savinkova, L.; Oshchepkov, D.; Kolchanov, N.A.; et al. Domestication Explains Two-Thirds of Differential-GeneExpression Variance between Domestic and Wild Animals; The Remaining One-Third Reflects Intraspecific and Interspecific Variation. Animals 2021, 11, 2667. https://doi.org/10.3390/ani11092667

Received: 19 August 2021

Accepted: 6 September 2021

Published: 10 September 2021

Publisher's Note: MDPI stays neutral with regard to jurisdictional claims in published maps and institutional affiliations.

Copyright: (C) 2021 by the authors Licensee MDPI, Basel, Switzerland. This article is an open access article distributed under the terms and conditions of the Creative Commons Attribution (CC BY) license (https:// creativecommons.org/licenses/by/ $4.0 /)$.
Institute of Cytology and Genetics, Siberian Branch of Russian Academy of Sciences, 630090 Novosibirsk, Russia; ichadaeva@bionet.nsc.ru (I.C.); pon.petr@gmail.com (P.P.); korimma@gmail.com (R.K.); valya@bionet.nsc.ru (V.S.); mantis_anton@bionet.nsc.ru (A.B.); klimova@bionet.nsc.ru (N.K.); shikhsvt@bionet.nsc.ru (S.S.);

lksav@bionet.nsc.ru (L.S.); diman@bionet.nsc.ru (D.O.); kol@bionet.nsc.ru (N.A.K.); markel@bionet.nsc.ru (A.M.)

* Correspondence: pon@bionet.nsc.ru

Simple Summary: Before genomes were sequenced, zoologists had discovered destabilizing selection as a general pattern of animal domestication that in foxes and minks had yielded fur colors never seen in the wild. Today, known genomes of humans and domestic and wild animals arouse interest in a common whole-genome pattern of animal domestication that may at least explain differences between the effects of natural and artificial environments on organisms. Accordingly, here we identified genes differing in expression between tame and aggressive rats (a laboratory domestication model) to compare them with all such known changes of genes' activity (available in databases) in other domestic versus wild animals (e.g., dogs versus wolves). The results show that the majority of these genes changed their expression similarly among all the domestic versus wild animals studied, i.e., explained two-thirds of the variance, while the remaining one-third reflected animal intraspecific and interspecific variation, just as the gold standard of variation in nature. Accordingly, here we found that the artificial environment of domestic animals alters activities of genes in the same direction as that seen in corresponding human genes during human diseases, whereas the natural environment maintains a normal gene expression pattern in wild animals (matching human health).

Abstract: Belyaev's concept of destabilizing selection during domestication was a major achievement in the XX century. Its practical value has been realized in commercial colors of the domesticated fox that never occur in the wild and has been confirmed in a wide variety of pet breeds. Many human disease models involving animals allow to test drugs before human testing. Perhaps this is why investigators doing transcriptomic profiling of domestic versus wild animals have searched for breed-specific patterns. Here we sequenced hypothalamic transcriptomes of tame and aggressive rats, identified their differentially expressed genes (DEGs), and, for the first time, applied principal component analysis to compare them with all the known DEGs of domestic versus wild animals that we could find. Two principal components, PC1 and PC2, respectively explained $67 \%$ and $33 \%$ of differential-gene-expression variance (hereinafter: $\log _{2}$ value) between domestic and wild animals. PC1 corresponded to multiple orthologous DEGs supported by homologs; these DEGs kept the $\log _{2}$ value sign from species to species and from tissue to tissue (i.e., a common domestication pattern). PC2 represented stand-alone homologous DEG pairs reversing the $\log _{2}$ value sign from one species to another and from tissue to tissue (i.e., representing intraspecific and interspecific variation).

Keywords: Rattus norvegicus; domestication; RNA-Seq; qPCR; differentially expressed gene; principal component analysis; intraspecific variety; interspecific variation 


\section{Introduction}

One of the key achievements of genetics in the XX century is Belyaev's concept of destabilizing selection during animal domestication as the most common pattern of domestication, namely: "In a genetic and biochemical sense, what may be selected for are changes in the regulation of genes - that is, in the timing and the amount of gene expression rather than changes in individual structural genes. Selection having such an effect is called by me destabilizing selection. The selection becomes destabilizing when it affects, directly or indirectly, the systems of neuroendocrine control of ontogenesis. This seems always to be the case when some new stressful factors appear in the environment, or when stresses usual for the species increase in strength." [1]. This breakthrough summed up the results of longterm unique experiments on both mink (e.g., [2]) and fox (e.g., [3]) domestication as well as on mice as a laboratory model of human diseases (e.g., [4]). Among these experiments was our study on how emotionally mice respond to stress [5]. The practical value of Belyaev's concept has been realized in a huge collection of commercial fur colors-e.g., "Amber-gold pastel," "Ashen," "Beige," "Black crystal," "Cobalt," “Ermine-like," "Peach," "“Pearl," Platinum," "Purple," "Silver sable-like," "Steel-blue," and "Straw,"-rarely or never seen in the wild [6]. The concept's fundamental importance has found confirmation in a large variety of breeds of dogs [7], cats [8], pigs [9], cows [10], horses [11], sheep [12], goats [13], chickens [14], ducks [15], geese [16], and other domestic animals [17] as well as in artificial shelters and additional feeding for wild animals in wildlife for saving them [18]. On the basis of Belyaev's concept [1], a laboratory model of animal domestication by humans has been created using outbred lines of tame and aggressive rats artificially bred [19] for performance on a standard glove test [20]. Moreover, within translational biomedicine [21], a lot of the human disease models involving domestic and laboratory animals, including transgenic ones [22], are actively researched to eventually conduct preclinical trials of drugs intended for human treatments. Perhaps that is why the majority of transcriptomeprofiling studies on domestic versus wild animals are still focused on the search for the species specificity of differentially expressed genes (DEGs) that has practical value [23-29] rather than for common patterns of domestication. An exception from the mainstream in genome-wide studies on animals is a comparison of the human variome with differences between domestic and wild animals, where the researchers have generalized their results by means of the new concept of self-domestication syndrome, the symptoms of which include autism spectrum disorders [30], although the idea of human self-domestication is still debatable [31].

Among the studies fitting Belyaev's concept of destabilizing selection during domestication [1], in our previous works, we have measured the murine emotional response under stress [5]. Next, our genome-wide study of the CpG-islands within gene promoters in humans, chimpanzees, gorillas, and orangutans identified the evolution of brain active promoters in the human lineage toward their increased epigenetic regulation plasticity [32]. Moreover, we have conducted a genome-wide study on single-nucleotide polymorphisms (SNP) within gene promoters of the human nervous system and found that natural selection equally supports propensities to domination and subordination, which must be inherited from parent to offspring; we proved this idea using F1 hybrid mice [33]. Additionally, by quantitative polymerase chain reaction (qPCR), we have identified seven hypothalamic DEGs of tame versus aggressive rats [34] as the above-mentioned laboratory model of animal domestication $[19,20]$. Finally, applying the factor analysis [35] to these seven rat DEGs, we for the first time observed that artificial selection for behavior, adaptation to laboratory living conditions, and intraspecific variety equally well explain the differentialgene-expression variance of tame versus aggressive rats [36]. That is why the present work generalizes our above-mentioned qPCR-based findings at the whole-genome scale. Biomedical applications of the results are discussed at the end of the paper. 


\section{Materials and Methods}

\subsection{Animals}

The study was performed on adult male gray rats (Rattus norvegicus) selectively bred for over 90 generations for either aggressive or domesticated behavior (as two outbred lines) under standard conditions of the Conventional Animal Facility of the Institute of Cytology and Genetics (ICG), the Siberian Branch of the Russian Academy of Sciences (SB RAS; Novosibirsk, Russia), as described elsewhere $[19,20,37]$. The total number of rats was 22 (11 aggressive and 11 domesticated), each weighing 250-270 g and 4 months old, all from different unrelated litters. All the rats were decapitated. Following a handbook [38], we extracted samples of the hypothalamus, which were then flash-frozen in liquid nitrogen and stored at $-70{ }^{\circ} \mathrm{C}$ until use. We focused on the hypothalamus as a universal brain region most frequently used in studies on aggressiveness of female and male animals of all ages (for review, see e.g., [39]). Every effort was made to minimize the number of animals studied and their suffering.

\subsection{RNA-Seq}

For RNA isolation, approximately $100 \mathrm{mg}$ of tissue was used. Total RNA from hypothalamus samples of tame $(n=3)$ and aggressive $(n=3)$ rats for sequencing was isolated using the TRIzol ${ }^{\mathrm{TM}}$ reagent (Invitrogen, Carlsbad, CA, USA, cat. \#15596018) according to the manufacturer's protocol. By means of the mirVana ${ }^{\mathrm{TM}} \mathrm{Kit}$ (miRNA Isolation Kit without phenol, Thermo Fisher Scientific, AB-AM1561), the RNA was separated. The total RNA after separation on mirVana columns was analyzed quantitatively by means of an Invitrogen Qubit ${ }^{\mathrm{TM}} 2.0$ fluorometer (Invitrogen/Life Technologies, Carlsbad, CA, USA).

The quality of total RNA was assessed with the RNA Nano Kit on an Agilent Bioanalyzer 2100 bioanalyzer (Agilent, Santa-Clara, CA, USA). Samples with RNA Integrity Numbers (RINs) of 7.0 to 8.0 were chosen for further analysis. To obtain a highly purified mRNA fraction, the Dynabeads mRNA Purification Kit (Invitrogen) was employed in accordance with the manufacturer's protocol. For purification, $5 \mu \mathrm{g}$ of the RNA fraction depleted of small RNAs was used. The absence of significant degradation of RNA and the presence of rRNA impurities at less than $20 \%$ were monitored on a bioanalyzer with the RNA Pico Kit. To create barcoded RNA-Seq libraries, 15-30 ng of mRNA was used; the ScriptSeq ${ }^{\mathrm{TM}}$ v2 RNA-Seq Library Preparation Kit (epicenter ${ }^{\circledR}$, Madison, WI, USA) was utilized according to the manufacturer's protocol. When amplifying the libraries, we carried out 13 polymerase chain reaction (PCR) cycles; the final purification was performed on AMPure XP magnetic beads. The quality of the obtained libraries and their molarity were checked on a bioanalyzer using the DNA High Sensitivity kit; before loading, the library was diluted 1:10. The molarity of the 24 obtained libraries was in the range of 10,000-47,000 pmol/L. The libraries were pooled in equimolar amounts, adjusted to a concentration of $2 \mathrm{nM}$, and transferred to the Multi-Access Center of Genomic Research (ICG SB RAS, Novosibirsk, Russia) for sequencing on an Illumina NextSeq 550 instrument in a NextSeq ${ }^{\circledR} 500 / 550$ High Output Kit v2 cassette (75 cycles) under the assumption of a direct read of 75 nucleotides, with at least 40 million reads. The total volume of sequencing for the 6 libraries was 219,086,104 reads, which were finally deposited in the NCBA SRA database (ID = PRJNA668014) [40].

\subsection{Mapping of RNA Sequences to the R. norvegicus Reference Genome}

The quality of the obtained raw Fastq files was checked and analyzed with FastQC. To improve the quality of the raw reads, we employed the Trimmomatic tool [41] by these procedures: removing a base from either the start or end position if the quality was low, trimming bases by a sliding-window method, and removing any remaining reads that are $<36$ bases long. The trimmed reads were aligned to the annotated $R$. norvegicus genome retrieved from the UCSC database (RGSC Rnor_6.0, UCSC version Rn6, July 2014 assembly). Alignment was performed in TopHat2 [42]. The alignments were postprocessed into sorted BAM files by means of SAMTools version 1.4 [43]. Reads were attributed to genes using 
the htseq-count tool from the "HTSeq" framework version 0.7.2 [44] based on gtf-files with coordinates of genes from Rnor_6.0 and an indexed SAM file. Differential expression analysis was performed in DESeq2 [45] on the IRIS web server, which is publicly available at http:/ / bmbl.sdstate.edu/IRIS/ (accessed on 16 January 2020). Genes were considered differentially expressed if they showed an adjusted $p$ value of less than 0.05 to ensure statistical significance [46], as widely accepted in the case of DEGs in domestic vs. wild animals (e.g., $[23,25,29])$.

\section{4. $q P C R$}

As independent selective verification of the DEGs identified using the above-described RNA-Seq (see Sections 2.2 and 2.3), in this work, we for the first time examined the total RNA from only the remaining hypothalamus samples of tame $(n=8)$ and aggressive $(n=8)$ rats, which was intended only for this qPCR control assay. That total RNA was also isolated with TRIzol and then purified on Agencourt RNAClean XP Kit magnetic beads (Beckman, \#A63987). The amount of RNA was evaluated on a Qubit ${ }^{\mathrm{TM}} 2.0$ fluorometer (Invitrogen/Life Technologies) with a reagent kit (RNA High Sensitivity, Invitrogen \# In = Q32852) according to the manufacturer's instructions. cDNA was synthesized with Reverse Transcription Kit reagents (Syntol, \#OT-1). Oligonucleotide primers for qPCR were designed in PrimerBLAST [47], as shown in Table 1. qPCR was conducted with the EVA Green I Kit following the manufacturer's instructions. The qPCR was carried out in three technical replicates on LightCycler ${ }^{\circledR} 96$ (Roche, Basel, Basel-Stadt, Switzerland). The efficiency of the qPCR was determined by means of a series of cDNA dilutions (standards). Four rat genes-B2m ( $\beta$-2-microglobulin), Hprt1 (hypoxanthine phosphoribosyltransferase 1), Ppia (peptidylprolyl isomerase A), and Rpl30 (ribosomal protein L30) — served as reference genes according to published recommendations [48-51].

Table 1. For quantitative polymerase chain reaction (qPCR), primers were selected using Web service PrimerBLAST [47].

\begin{tabular}{ccccc}
\hline No. & Rat Gene & NCBI Gene ID & Direct, $\mathbf{5}^{\prime} \rightarrow \mathbf{3}^{\prime}$ & Reverse, $\mathbf{5}^{\prime} \rightarrow \mathbf{3}^{\prime}$ \\
\hline $\mathbf{i}$ & $\mathbf{i i}$ & $\mathbf{i i i}$ & $\mathbf{i v}$ & $\mathbf{v}$ \\
\hline \multicolumn{4}{c}{ DEG Identifiedin Hypothalamus of Tame versus Aggressive Rats [This Work] } \\
1 & Apobec1 & 25383 & CGCCGCAACATAAGCTCCCGA & TGCTGTGCCTTCCTCCCCAGTTG \\
2 & Ascl3 & 246301 & CCTCTGCTGCCCTTTTCCAG & ACTTGACTCGCTGCCTCTCT \\
3 & Defb17 & 641658 & TGGTAGCTTGGACTTGAGGAAAGAA & TGCAGCAGTGTGTTCCAGGTC \\
& & & Reference Genes & \\
4 & $B 2 m$ & 24223 & GTGTCTCAGTTCCACCCACC & TTACATGTCTCGGTCCCAGG \\
5 & Hprt1 & 24465 & TCCCAGCGTCGTGATTAGTGA & CCTTCATGACATCTCGAGCAAG \\
6 & Ppia & 25518 & TTCCAGGATTCATGTGCCAG & CTTGCCATCCAGCCACTC \\
7 & Rpl30 & 64640 & CATCTTGGCGTCTGATCTTG & TCAGAGTCTGTTTGTACCCC \\
\hline
\end{tabular}

Notes. The rat differentially expressed genes (DEGs) subjected to this qPCR verification: Apobec1, apolipoprotein B mRNA editing enzyme catalytic subunit 1; Ascl3, achaete-scute family bHLH transcription factor 3; Defb17, defensin $\beta$ 17; B2m, $\beta$-2-microglobulin [48]; Hprt1, hypoxanthine phosphoribosyltransferase 1 [49]; Ppia, peptidylprolyl isomerase A [50]; and Rpl30, ribosomal protein L30 [51].

Finally, using these qPCR-based magnitudes together with the standard software Statistica (Statsoft ${ }^{\mathrm{TM}}$, Tulsa, OK, USA), we selectively verified the aforementioned RNASeq data (see Section 2.2) by both the Mann-Whitney $U$ test and Fisher's Z-test as well as both linear and rank correlations.

\subsection{DEGs of Domestic Animals versus Their Wild Congeners}

In this work, we utilized publicly available independent experimental RNA-Seq datasets from transcriptomes of domestic animals compared with their wild congeners [23-29]; these data were statistically significant according to Fisher's Z-test, with corrections for multiple comparisons $\left(\mathrm{P}_{\mathrm{ADJ}}<0.05\right)$, as published by their authors (see, the PubMed database [52]) and outlined in Table 2. 
Table 2. The investigated genome-wide transcriptomes of domestic versus wild animals, all the data that we could find in PubMed [52].

\begin{tabular}{|c|c|c|c|c|c|}
\hline \# & Wild Animals & Domestic Animals & Tissue & $\mathbf{N}_{\text {DEG }}$ & [Ref] \\
\hline 1 & aggressive foxes (Vulpes vulpes) & tame foxes ( $V$. vulpes) & pituitary & 327 & [23] \\
\hline 2 & wolves (Canis familiaris) & dogs (C. lupus) & blood & 450 & {$[24]$} \\
\hline 3 & wolves (C. lupus) & dogs (C. familiaris) & frontal cortex & 13 & [25] \\
\hline 4 & Boars (Sus scrofa) & pigs (S. scrofa) & frontal cortex & 30 & [25] \\
\hline 5 & cavy (Cavia aperea) & guinea pigs (C. porcellus) & frontal cortex & 883 & [25] \\
\hline 6 & wild rabbits (Oryctolagus cuniculus) & domestic rabbits (O. cuniculus domesticus) & frontal cortex & 17 & [25] \\
\hline 7 & aggressive rats ( $R$. norvegicus) & tame rats (Rattus norvegicus) & frontal cortex & 20 & [25] \\
\hline 8 & boars (S. scrofa) & pigs (S. scrofa) & frontal cortex & 34 & [26] \\
\hline 9 & boars (S. scrofa) & pigs (S. scrofa) & pituitary & 22 & [27] \\
\hline 10 & wild rabbits (O. cuniculus) & domestic rabbits (O. cuniculus domesticus) & parietal-temporal cortex & 216 & [28] \\
\hline 11 & wild rabbits (O. cuniculus) & domestic rabbits (O. cuniculus domesticus) & amygdala & 118 & [28] \\
\hline 12 & wild rabbits (O. cuniculus) & domestic rabbits (O. cuniculus domesticus) & hypothalamus & 43 & [28] \\
\hline 13 & wild rabbits (O. cuniculus) & domestic rabbits (O. cuniculus domesticus) & hippocampus & 100 & [28] \\
\hline 14 & wild chicken (G. gallus) & domestic chicken (Gallus gallus) & pituitary & 474 & [29] \\
\hline$\Sigma$ & 7 wild animal species: & 7 domestic animal species: & 7 tissues & 2347 & 7 Refs \\
\hline
\end{tabular}

As a result, 2347 DEGs were analyzed, which represented seven tissues of seven domestic animal species and seven of their wild congeners, as readers can see in in the last row of Table 2. Figure 1 represents an algorithmic flowchart detailing the verification of the DEGs found in this work in the hypothalamus of tame versus aggressive rats with respect to their known homologous DEGs in domestic animals versus their wild congeners, as independently reported by others (Table 2), as depicted by the "TEST DATA" area. In brief, we first searched for homologous genes of rats and other animals among all analyzed genes (STEP 1). Next, applying a principal component analysis to these pairwise expressionfold-change combinations of genes-homologs, we found two principal components PC1 and PC2 (STEP 2). Then, we conducted a statistical analysis of the correlation between either multiple-homolog orthologous DEGs or single orthologous DEGs, namely, we tested whether there are the same (PC1) or opposite (PC2) signs of the $\log _{2}$-transformed ratio of an expression level of a given gene in tame rats to that in aggressive rats (hereinafter: log2-value) within an orthologous DEG pair being tested (STEP 3). Finally, using both linear and rank correlation analysis, we found significant positive correlations between fold changes of the multiple homologous DEGs (PC1) and significant negative correlations between fold changes of the only single homologous DEGs (PC2); this is STEP 4 in Figure 1.

\subsection{Statistical Analysis}

As depicted in Figure 1, during our statistical analysis, we compiled standard statistical $2 \times 2$ tables, which served as input data for the standard software Statistica (Statsoft ${ }^{\mathrm{TM}}$, Tulsa, OK, USA) in its pipeline "Statistics" $\rightarrow$ "Nonparametric" $\rightarrow$ "Table $2 \times 2$." This brought us to Fisher's exact test, Pearson's $\chi^{2}$ test, and binomial distribution analysis to test the significance of the results (Figure 1). Likewise, by means of the same toolbox with proper options, we carried out the Mann-Whitney $U$ test, Fisher's Z-test (see Section 2.4), and principal component analysis (Figure 1). 


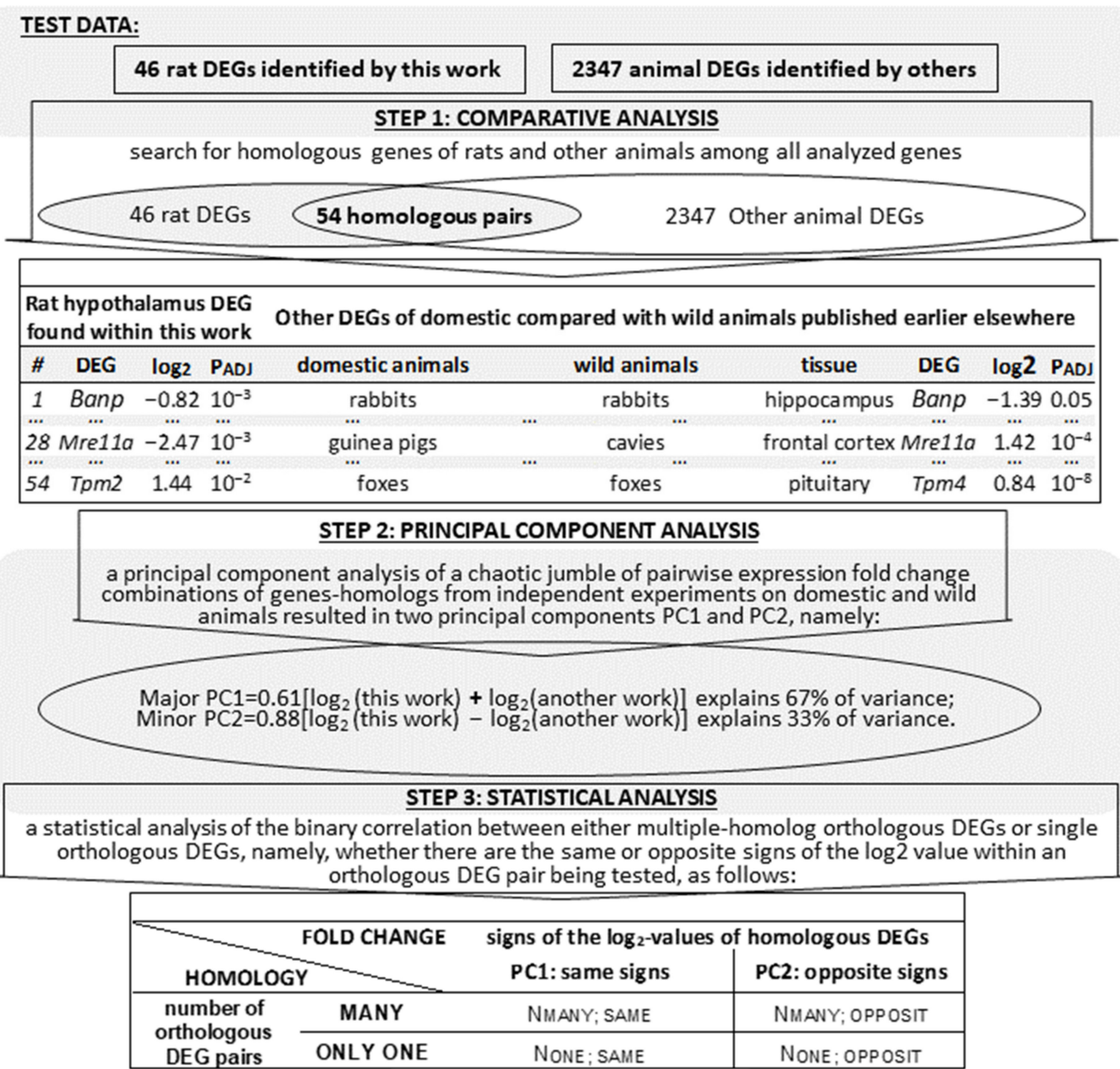

STEP 4: CORRELATION ANALYSIS

(a) significant positive correlations between fold changes of the multiple homologous DEGs; (b) significant negative correlation between fold changes of the single homologous DEGs.

Figure 1. An algorithmic flowchart illustrating the verification of the DEGs found in this study in the hypothalamus of tame versus aggressive rats with respect to their known homologous DEGs in domestic animals compared with their wild congeners, as independently reported by others. Legend: $\log 2$, the $\log _{2}$-transformed fold change (i.e., the ratio of a domestic-animal gene expression level to that in wild animals); PC1 and PC2: first and second principal components, respectively.

\section{Results}

\subsection{RNA-Seq and Mapping to the Reference Rat Genome}

Using an Illumina NextSeq 550 system, we sequenced the hypothalamus transcriptome of three tame adult male rats and that of three aggressive ones. The rats had no family relations and represented two outbred lines (see Section 2). From 219,086,104 raw reads (75 nt, deposited in the NCBI, PRJNA668014) 184,991,379 reads (84\%) were mapped to reference genome Rn6 (Table 3). This allowed us to identify 14,039 genes expressed within the hypothalamus of adult male rats under the experimental conditions used (Table 3 ). According to Fisher's Z-test, 1025 of these genes (7\%) were statistically significantly differentially expressed between tame and aggressive rats in their hypothalamus at the commonly ac- 
cepted confidence threshold $p<0.05$, as presented in Table 3. To minimize false positive error rates, we applied the Benjamini correction for multiple comparisons, which finally resulted in 46 DEGs in the hypothalamus of the tame versus aggressive rats under study (Table 3); the DEGs are listed in Table 4. In particular, rat gene Ascl3 encoding achaete-scute family bHLH transcription factor 3 turned out to be the best DEG within the hypothalamus of the tame versus aggressive rats owing to its smallest $\mathrm{P}_{\mathrm{ADJ}}$ value, $10^{-8}$. This DEG has a $\log 2$ value of 3.99, as shown in Table 4, row \#1.

Table 3. A summary of transcriptome sequencing in the hypothalamus of three tame rats and three aggressive ones (all unrelated).

\begin{tabular}{cc}
\hline Group & Tame vs. Aggressive Rats \\
\hline Total sequence reads (NCBI SRA, ID = PRJNA668014) & $219,086,104$ \\
Reads mapped to reference rat genome RGSC Rnor_6.0, & $184,991,379(84.44 \%)$ \\
UCSC Rn6, July 2014 $(\%)$ & 14,039 \\
Expressed genes identified & 1025 \\
Candidate DEGs identified ( $p$ value $<0.05 ;$ Fisher's Z-test) & 46 \\
Statistically significant DEGs (P ADJ $<0.05$, Benjamini correction) &
\end{tabular}

Table 4. The statistically significant DEGs in the hypothalamus of tame versus aggressive rats bred artificially during 90 generations from the same common ancestral subpopulation.

\begin{tabular}{|c|c|c|c|c|c|}
\hline \multicolumn{3}{|r|}{ Rat Gene } & \multicolumn{3}{|c|}{ Differential Expression } \\
\hline No. & Symbol & Name & $\log 2$ & $p$ & $P_{A D J}$ \\
\hline 1 & Ascl3 & achaete-scute family bHLH transcription factor 3 & 3.99 & $10^{-12}$ & $10^{-8}$ \\
\hline 2 & Morn1 & MORN repeat containing 1 & 1.24 & $10^{-10}$ & $10^{-6}$ \\
\hline 3 & Krt2 & keratin 2 & -1.65 & $10^{-8}$ & $10^{-4}$ \\
\hline 4 & Banp & Btg3 associated nuclear protein & -0.82 & $10^{-6}$ & $10^{-3}$ \\
\hline 5 & Mre11 & MRE11 homolog, double strand break repair nuclease & -2.47 & $10^{-6}$ & $10^{-3}$ \\
\hline 6 & $R b m 3$ & RNA binding motif protein 3 & 1.04 & $10^{-6}$ & $10^{-3}$ \\
\hline 7 & Fcgr3a & Fc fragment of IgG receptor IIIa & 2.06 & $10^{-6}$ & $10^{-2}$ \\
\hline 8 & Plac8 & placenta associated 8 (synonym: onzin) & 2.83 & $10^{-5}$ & $10^{-2}$ \\
\hline 9 & $C d 22$ & CD22 molecule & 2.85 & $10^{-5}$ & $10^{-2}$ \\
\hline 10 & Apobec1 & apolipoprotein B mRNA editing enzyme catalytic subunit 1 & 1.87 & $10^{-5}$ & $10^{-2}$ \\
\hline 11 & Magee2 & MAGE family member E2 & -0.95 & $10^{-5}$ & $10^{-2}$ \\
\hline 12 & $H b b-b 1$ & hemoglobin, $\beta$ adult major chain & -3.97 & $10^{-5}$ & $10^{-2}$ \\
\hline 13 & Tpm2 & tropomyosin 2 & 1.44 & $10^{-5}$ & $10^{-2}$ \\
\hline 14 & Apobr & apolipoprotein B receptor & 1.56 & $10^{-5}$ & $10^{-2}$ \\
\hline 15 & Cenps & centromere protein $S$ & 1.63 & $10^{-4}$ & 0.05 \\
\hline 16 & Gale & UDP-galactose-4-epimerase & 1.15 & $10^{-4}$ & 0.05 \\
\hline 17 & Pcdhb9 & protocadherin $\beta 9$ & -1.01 & $10^{-4}$ & 0.05 \\
\hline 18 & $P 2 r x 4$ & purinergic receptor $\mathrm{P} 2 \mathrm{X} 4$ & 1.14 & $10^{-4}$ & 0.05 \\
\hline 19 & $R n 45 s$ & $45 S$ pre-ribosomal RNA & -1.62 & $10^{-4}$ & 0.05 \\
\hline 20 & $N r 4 a 3$ & nuclear receptor subfamily 4 , group A, member 3 & -1.29 & $10^{-4}$ & 0.05 \\
\hline 21 & Ghitm & growth hormone inducible transmembrane protein & 0.40 & $10^{-4}$ & 0.05 \\
\hline 22 & Shox 2 & short stature homeobox 2 & 6.18 & $10^{-4}$ & 0.05 \\
\hline 23 & Insig1 & insulin induced gene 1 & 0.49 & $10^{-4}$ & 0.05 \\
\hline 24 & Orail & ORAI calcium release-activated calcium modulator 1 & 1.83 & $10^{-4}$ & 0.05 \\
\hline 25 & Thrsp & thyroid hormone responsive & 1.43 & $10^{-4}$ & 0.05 \\
\hline 26 & Spint1 & serine peptidase inhibitor, Kunitz type 1 & -0.91 & $10^{-4}$ & 0.05 \\
\hline 27 & Liph & lipase $\mathrm{H}$ & 3.28 & $10^{-4}$ & 0.05 \\
\hline 28 & Pla2g2c & phospholipase A2, group IIC & -1.08 & $10^{-4}$ & 0.05 \\
\hline 29 & Lilrb3l & leukocyte immunoglobulin-like receptor, subfamily B, member 3-like & 7.34 & $10^{-4}$ & 0.05 \\
\hline 30 & Hspa1b & heat shock protein family A (Hsp70) member 1B & -1.25 & $10^{-4}$ & 0.05 \\
\hline 31 & Nmral1 & NmrA-like redox sensor 1 & 1.18 & $10^{-4}$ & 0.05 \\
\hline 32 & Mogat2 & monoacylglycerol O-acyltransferase 2 & 2.08 & $10^{-4}$ & 0.05 \\
\hline 33 & Defb17 & defensin $\beta 17$ & 6.02 & $10^{-4}$ & 0.05 \\
\hline 34 & Sh3bgr & SH3 domain binding glutamate-rich protein & 1.11 & $10^{-4}$ & 0.05 \\
\hline
\end{tabular}


Table 4. Cont.

\begin{tabular}{|c|c|c|c|c|c|}
\hline \multicolumn{3}{|r|}{ Rat Gene } & \multicolumn{3}{|c|}{ Differential Expression } \\
\hline No. & Symbol & Name & $\log 2$ & $p$ & $P_{A D J}$ \\
\hline 35 & Eif2b3 & eukaryotic translation initiation factor $2 \mathrm{~B}$ subunit $\gamma$ & 0.63 & $10^{-4}$ & 0.05 \\
\hline 36 & Fcrl2 & Fc receptor-like 2 & 1.12 & $10^{-4}$ & 0.05 \\
\hline 37 & Fuca1 & $\alpha$-L-fucosidase 1 & 1.10 & $10^{-4}$ & 0.05 \\
\hline 38 & Bdh1 & 3-hydroxybutyrate dehydrogenase 1 & 0.37 & $10^{-4}$ & 0.05 \\
\hline 39 & Rps16 & ribosomal protein $\mathrm{S} 16$ & 1.32 & $10^{-3}$ & 0.05 \\
\hline 40 & Ifi $27 l 2 b$ & interferon- $\alpha$-inducible protein 27 like $2 B$ & 2.36 & $10^{-3}$ & 0.05 \\
\hline 41 & Ifi47 & interferon- $\gamma$-inducible protein 47 & 1.47 & $10^{-3}$ & 0.05 \\
\hline 42 & Mcm10 & minichromosome maintenance 10 replication initiation factor & -1.98 & $10^{-3}$ & 0.05 \\
\hline 43 & Fjx1 & four-jointed box kinase 1 & 0.83 & $10^{-3}$ & 0.05 \\
\hline 44 & Zmym6 & zinc finger MYM-type containing 6 & -0.59 & $10^{-3}$ & 0.05 \\
\hline 45 & Use1 & unconventional SNARE in the ER 1 & 1.11 & $10^{-3}$ & 0.05 \\
\hline 46 & Fus & FUS RNA-binding protein & 0.48 & $10^{-3}$ & 0.05 \\
\hline
\end{tabular}

Note: $\log 2$, see the legend of Figure 1; $p$, the statistical significance according to Fisher's Z-test without the Benjamini correction for multiple comparisons.

3.2. qPCR Selective Verification of the DEGs Identified in this Work in the Hypothalamus of Tame versus Aggressive Rats

For this purpose, we selected three out of the 46 DEGs listed in Table 4, namely, Ascl3 (i.e., the above-mentioned best DEG), Apobec1, and Defb17, as shown in Table 5.

Additionally, separately, we prepared eight other tame adult male rats and eight other aggressive ones (all unrelated), who scored either " -3 " or " 3 " (Table 5) on a scale from -4 (the most aggressive rat) to 4 (the tamest rat) in the standard glove test [20]. It was performed 1 month before the extraction of hypothalamus samples to minimize the effects of the glove test on the results of this study (see Section 2). At the bottom of Table 5, we present our qPCR data on the three DEGs examined in the hypothalamus of the aggressive versus tame rats as mean \pm standard error of mean $\left(M_{0} \pm S E M\right)$ of their relative expression with respect to four reference genes $B 2 m, H p r t 1, P p i a$, and Rpl30 on the basis of three technical replicates. These qPCR values (expression levels) varied from 0.01 to 9.22. In three out of eight aggressive rats (\#3, \#4, and \#5), Defb17 expression levels in the hypothalamus were below the threshold of sensitivity under the experimental conditions where we reliably measured the expression of all the tested genes in all studied rats (except for these three cases, as indicated by "ND, not detected" in Table 5).

Moreover, in the rightmost column of Table 5, we present the results of averaging the expression levels of each of the three verified DEGs in the hypothalamus of the aggressive and tame rats examined. Figure 2 a shows graphical representation of these qPCR results.

In this figure, readers can see statistically significant overexpression of all the three examined DEGs in the hypothalamus of the tame male adult rats (white bars) compared with aggressive ones (grey bars) according to the qPCR data obtained in this work, in agreement with the expression levels detected in the transcriptome analysis (Table 4), as depicted by asterisks, each of which means $p<0.05$ in both the Mann-Whitney $U$ test and Fisher's Z-test, which are independent from one another. 


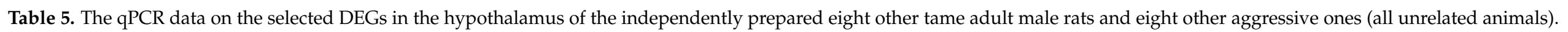

\begin{tabular}{|c|c|c|c|c|c|c|c|c|c|c|}
\hline \multicolumn{2}{|c|}{ Study Design } & \multicolumn{8}{|c|}{ Behavioral "Glove" Test [20] and the qPCR Data on Gene Expression [This Work] } & \\
\hline Rat & Set & 1 & 2 & 3 & 4 & 5 & 6 & 7 & 8 & \\
\hline \multirow{2}{*}{ Glove Test } & A & -3 & -3 & -3 & -3 & -3 & -3 & -3 & -3 & \\
\hline & $\mathbf{T}$ & 3 & 3 & 3 & 3 & 3 & 3 & 3 & 3 & \\
\hline$D E G$ & Set & \multicolumn{8}{|c|}{ Relative Expression with Respect to Four Reference Genes, qPCR, $\mathrm{M}_{0} \pm \mathrm{SEM}$} & TOTAL \\
\hline Ascl3 & A & $0.22 \pm 0.04$ & $0.14 \pm 0.03$ & $1.04 \pm 0.12$ & $0.11 \pm 0.03$ & $0.22 \pm 0.04$ & $0.14 \pm 0.02$ & $0.12 \pm 0.03$ & $0.12 \pm 0.03$ & $0.26 \pm 0.12$ \\
\hline \multirow{2}{*}{ Apobec1 } & A & $1.83 \pm 0.19$ & $0.71 \pm 0.27$ & $0.30 \pm 0.08$ & $0.58 \pm 0.17$ & $0.22 \pm 0.09$ & $0.58 \pm 0.14$ & $1.86 \pm 0.28$ & $0.93 \pm 0.16$ & $0.88 \pm 0.28$ \\
\hline & $\mathbf{T}$ & $2.09 \pm 0.62$ & $9.22 \pm 0.15$ & $1.12 \pm 0.05$ & $1.12 \pm 0.07$ & $4.03 \pm 0.73$ & $3.83 \pm 0.08$ & $3.49 \pm 1.13$ & $0.45 \pm 0.11$ & $3.17 \pm 1.07$ \\
\hline \multirow{2}{*}{ Defb17 } & $\mathbf{A}$ & $0.01 \pm 0.01$ & $0.01 \pm 0.01$ & ND & ND & ND & $0.01 \pm 0.01$ & $0.01 \pm 0.01$ & $0.01 \pm 0.01$ & $0.01 \pm 0.01$ \\
\hline & $\mathbf{T}$ & $1.57 \pm 0.22$ & $1.70 \pm 0.07$ & $2.12 \pm 0.51$ & $1.20 \pm 0.35$ & $0.66 \pm 0.04$ & $1.51 \pm 0.56$ & $0.90 \pm 0.04$ & $0.99 \pm 0.06$ & $1.33 \pm 0.35$ \\
\hline
\end{tabular}

Note. A, aggressive rats; $\mathrm{T}$, tame rats; $\mathrm{M}_{0} \pm \mathrm{SEM}$, mean \pm standard error of the mean for three technical replicates; ND, not detected. 


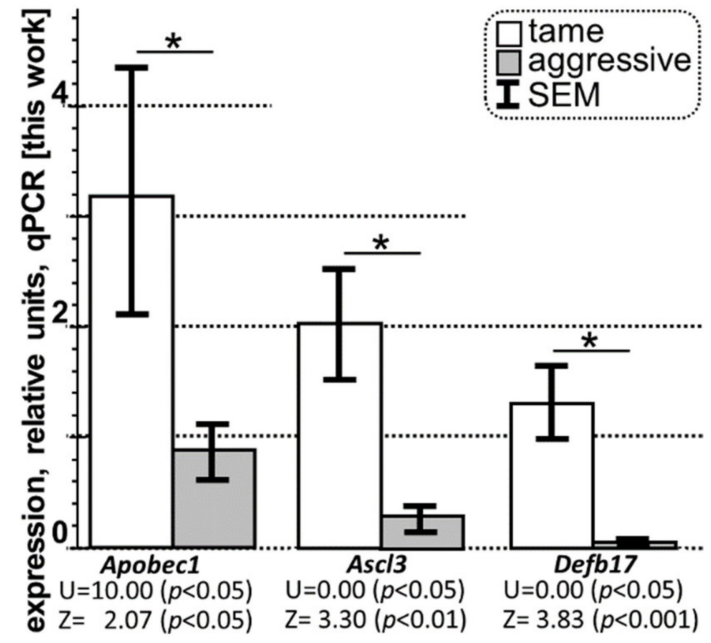

(a)

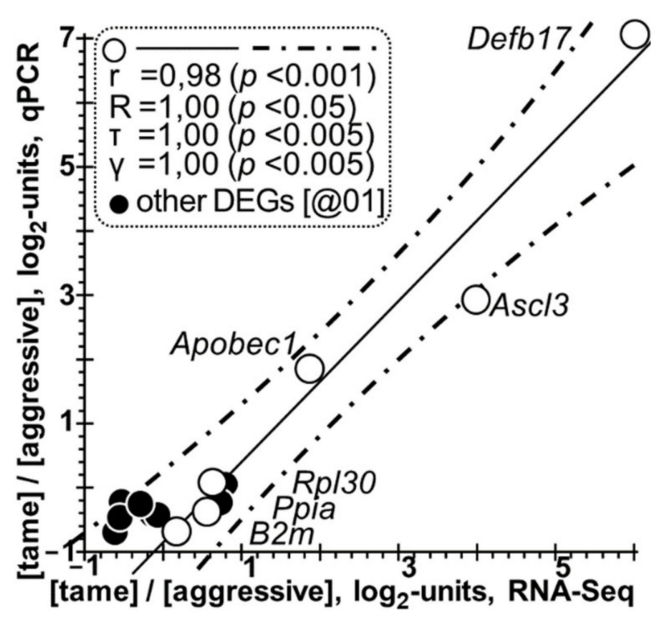

(b)

Figure 2. Selective qPCR-based verification of the DEGs identified in this work in the hypothalamus of tame versus aggressive rats. (a) In tame rats (white bars) versus aggressive rats (grey bars), all the three DEGs examined (i.e., Ascl3, Apobec1, and Defb17) are statistically significantly overexpressed in the hypothalamus (here, bar height: mean; error bars: standard error of mean [SEM]; and asterisks (i.e., the characters "*") denote statistical significance at $p<0.05$ according to both the Mann-Whitney $U$ test and Fisher's Z-test). (b) Statistically significant correlations between the log2 value of the three selected DEGs and three reference genes [i.e., B2m, Ppia, and Rpl30] in the hypothalamus of tame versus aggressive rats (open circles), as measured experimentally by RNA-Seq (X-axis) and qPCR ( $Y$-axis). Solid and dash-and-dot lines denote linear regression and boundaries of its $95 \%$ confidence interval calculated by means of software package Statistica (Statsoft ${ }^{\mathrm{TM}}$, Tulsa, OK, USA). Statistics: $\mathrm{r}, \mathrm{R}, \tau, \gamma$, and $p$ are coefficients of Pearson's linear correlation, Spearman's rank correlation, Kendall's rank correlation, Goodman-Kruskal generalized correlation, and their $p$ values (statistical significance), respectively. Filled circles depict the statistically significant DEGs in the hypothalamus of tame vs. aggressive rats according to the independent qPCR-based identification published elsewhere [34]. These qPCR [34] and RNA-Seq [this work] data are given in Table S1, where their Pearson's linear correlation is statistically significant, $\mathrm{r}=0.71$ at $p<0.05$ (hereinafter, see Supplementary Materials).

Figure $2 \mathrm{~b}$ presents statistically significant correlations between relative expression levels in the hypothalamus of tame versus aggressive rats, as measured experimentally by two methods [RNA-Seq (X-axis) and qPCR ( $Y$-axis)] independent from each other, with the results expressed in log2 values (see "Materials and methods") for the six genes, namely: three selected DEGs (i.e., Ascl3, Apobec1, and Defb17) and three reference genes (i.e., B2m, Ppia, and Rpl30) as depicted by open circles. In this figure, solid and dash-anddot lines represent linear regression and boundaries of its $95 \%$ confidence interval, as calculated by means of software package Statistica (Statsoft ${ }^{\mathrm{TM}}$, Tulsa, OK, USA). As one can see, the coefficients of Pearson's linear correlation ( $\mathrm{r}=0.89, p<0.001)$, Spearman's rank correlation $(\mathrm{R}=1.00, p<0.05)$, Kendall's rank correlation $(\tau=1.00, p<0.005)$, and Goodman-Kruskal generalized correlation $(\gamma=1.00, p<0.005)$ are statistically significant, while being independent from one another.

Moreover, the filled circles depict seven statistically significant DEGs in the hypothalamic samples of eight other tame rats versus eight other aggressive rats according to a qPCR-based identification protocol published in our previous work [34]. These RNASeq [this work] and qPCR [34] data are given in Table S1, where their Pearson's linear correlation is statistically significant too, namely: $\mathrm{r}=0.71$ at $p<0.05$ (hereinafter, see Supplementary Materials). Moreover, as readers can see here, all the seven independently identified DEGs do not go beyond the boundaries of the $95 \%$ confidence interval of the linear regression under consideration (i.e., they are between the two dash-and-dot lines). 
Summing Figure 2 up, both the nonparametric Mann-Whitney $U$ test and parametric Fisher's Z-test as well as Pearson's linear correlation, Goodman-Kruskal generalized correlation, and Spearman's and Kendall's rank correlations taken together independently indicate that in this study, the qPCR data on the hypothalamus of eight tame adult male rats compared with eight aggressive ones statistically significantly confirm the DEGs found in the hypothalamus of three other tame adult male rats versus three other aggressive ones (all unrelated animals). This confirmation means statistical robustness of the DEGs identified in this work.

3.3. Verification of the DEGs Found Here in the Hypothalamus of Tame versus Aggressive Rats with Respect to Their Known Homologous DEGs in Domestic and Wild Animals (All Data That We Could Find)

In this study, we for the first time verified the DEGs identified by us in the hypothalamus of tame versus aggressive rats with respect to their known homologous DEGs in domestic animals compared with their wild congeners as reported by others (Figure 1 and description in Section 2). With this in mind, to the 46 above-mentioned hypothalamic DEGs of tame versus aggressive adult male rats (Table 4), we first of all added 14 independent publicly available RNA-Seq datasets on domestic versus wild animals [23-29], entitled "TEST DATA" in Figure 1 and characterized in Table 2. There, to minimize false positive error rates, we took into account only the statistically significant DEGs (according to the Benjamini correction for multiple comparisons) published in relevant articles cited in the rightmost column of Table 2. This procedure eventually resulted in 2347 DEGs in seven tissues of seven pairs of domestic versus wild cognate animals (Table 2: bottom row).

As depicted by a Venn diagram in Figure 1 (STEP 1), next, we managed to compile 54 pairs of homologous DEGs (listed in Table 6), where each pair contains one DEG taken from Table 4 (i.e., columns i to iv of Table 6) as well as its homologous DEG chosen from the 2347 DEGs characterized in Table 2 as detailed in columns v to xi of Table 6.

Table 6. The hypothalamic DEGs of tame versus aggressive rats found in this work in comparison with their known homologous DEGs in domestic animals versus their wild congeners as reported by others.

\begin{tabular}{|c|c|c|c|c|c|c|c|c|c|c|}
\hline \multirow[t]{2}{*}{ \# } & \multicolumn{3}{|c|}{$\begin{array}{c}\text { Hypothalamic DEGs, } \\
\text { Tame vs. Aggressive Rats }\end{array}$} & \multicolumn{7}{|c|}{ DEGs Within the Tissues of the Domestic Animals versus Their Wild Congeners } \\
\hline & DEG & $\log 2$ & $\mathbf{P}_{\mathrm{ADJ}}$ & Tame/Domestic & Wild/Aggressive & Tissue & $D E G$ & $\log 2$ & $\mathbf{P}_{\mathrm{ADJ}}$ & [Ref] \\
\hline i & ii & iii & iv & $\mathbf{v}$ & vi & vii & viii & ix & $\mathbf{x}$ & $\mathbf{x i}$ \\
\hline 1 & Banp & -0.82 & $10^{-3}$ & rabbits & rabbits & hippocampus & Banp & -1.39 & 0.05 & [28] \\
\hline 2 & Banp & -0.82 & $10^{-3}$ & rabbits & rabbits & $\begin{array}{l}\text { parietal-temporal } \\
\text { cortex }\end{array}$ & Banp & -1.21 & $10^{-2}$ & [28] \\
\hline 3 & $C d 22$ & 2.85 & $10^{-2}$ & dogs & wolves & blood & $\mathrm{Cd} 22$ & 2.34 & 0.05 & [24] \\
\hline 4 & $C d 22$ & 2.85 & $10^{-2}$ & foxes & foxes & pituitary & $\mathrm{Cd} 22$ & 0.32 & $10^{-2}$ & [23] \\
\hline 5 & Defb17 & 6.02 & 0.05 & rabbits & rabbits & $\begin{array}{l}\text { parietal-temporal } \\
\text { cortex }\end{array}$ & Defb1 & 1.19 & $10^{-2}$ & [28] \\
\hline 6 & Eif $2 b 3$ & 0.63 & 0.05 & guinea pigs & cavy & frontal cortex & Eif2b3 & 0.72 & $10^{-3}$ & [25] \\
\hline 7 & Fcgr3a & 2.06 & $10^{-2}$ & rabbits & rabbits & $\begin{array}{l}\text { parietal-temporal } \\
\text { cortex }\end{array}$ & Fcgr $3 b$ & 1.35 & $10^{-2}$ & [28] \\
\hline 8 & Fcrl2 & 1.12 & 0.05 & foxes & foxes & pituitary & Fcrl1 & 0.43 & $10^{-2}$ & [23] \\
\hline 9 & Ghitm & 0.40 & 0.05 & guinea pigs & cavy & frontal cortex & Ghitm & -0.58 & 0.05 & [25] \\
\hline 10 & $H b b-b 1$ & -3.97 & $10^{-2}$ & dogs & wolves & blood & $H b b l$ & -5.92 & $10^{-8}$ & [24] \\
\hline 11 & $H b b-b 1$ & -3.97 & $10^{-2}$ & dogs & wolves & blood & $H b a 1$ & -4.06 & $10^{-5}$ & [24] \\
\hline 12 & $H b b-b 1$ & -3.97 & $10^{-2}$ & chicken & chicken & pituitary & Hbad & -1.07 & $10^{-2}$ & [29] \\
\hline 13 & $H b b-b 1$ & -3.97 & $10^{-2}$ & dogs & wolves & blood & $\mathrm{Hbm}$ & -6.46 & $10^{-6}$ & [24] \\
\hline 14 & $H b b-b 1$ & -3.97 & $10^{-2}$ & dogs & wolves & blood & $H b z 1$ & -7.10 & $10^{-2}$ & [24] \\
\hline
\end{tabular}


Table 6. Cont

\begin{tabular}{|c|c|c|c|c|c|c|c|c|c|c|}
\hline \multirow[t]{2}{*}{$\#$} & \multicolumn{3}{|c|}{$\begin{array}{l}\text { Hypothalamic DEGs, } \\
\text { Tame vs. Aggressive Rats }\end{array}$} & \multicolumn{7}{|c|}{ DEGs Within the Tissues of the Domestic Animals versus Their Wild Congeners } \\
\hline & DEG & $\log 2$ & $\mathbf{P}_{\text {ADJ }}$ & Tame/Domestic & Wild/Aggressive & Tissue & $D E G$ & $\log 2$ & $\mathbf{P}_{\text {ADJ }}$ & [Ref] \\
\hline i & ii & iii & iv & $\mathbf{v}$ & vi & vii & viii & ix & $\mathbf{x}$ & xi \\
\hline 15 & Hspa1b & -1.25 & 0.05 & rabbits & rabbits & $\begin{array}{l}\text { parietal-temporal } \\
\text { cortex }\end{array}$ & Hspa5 & -1.12 & 0.05 & [28] \\
\hline 16 & Hspa1b & -1.25 & 0.05 & rabbits & rabbits & amygdala & Hspa5 & -1.12 & 0.05 & {$[28]$} \\
\hline 17 & Hspa1b & -1.25 & 0.05 & rabbits & rabbits & $\begin{array}{l}\text { parietal-temporal } \\
\text { cortex }\end{array}$ & Hspa8 & -1.46 & $10^{-9}$ & {$[28]$} \\
\hline 18 & Hspa1b & -1.25 & 0.05 & rabbits & rabbits & amygdala & Hspa8 & -1.10 & 0.05 & [28] \\
\hline 19 & Hspa1b & -1.25 & 0.05 & rabbits & rabbits & hippocampus & Hspa8 & -1.36 & $10^{-2}$ & [28] \\
\hline 20 & Ifi2 $2712 b$ & 2.36 & 0.05 & chicken & chicken & pituitary & Ifi6 & -2.49 & $10^{-4}$ & [29] \\
\hline 21 & $K r t 2$ & -1.65 & $10^{-4}$ & chicken & chicken & pituitary & Krt17 & -1.12 & 0.05 & [29] \\
\hline 22 & Liph & 3.28 & 0.05 & guinea pigs & cavy & frontal cortex & Lipa & 0.84 & $10^{-2}$ & [25] \\
\hline 23 & Liph & 3.28 & 0.05 & guinea pigs & cavy & frontal cortex & Lipm & 1.45 & $10^{-2}$ & [25] \\
\hline 24 & Liph & 3.28 & 0.05 & chicken & chicken & pituitary & Lipml & 0.55 & $10^{-3}$ & [29] \\
\hline 25 & Mogat2 & 2.08 & 0.05 & rabbits & rabbits & hippocampus & Mogat1 & -1.93 & 0.05 & {$[28]$} \\
\hline 26 & Morn1 & 1.24 & $10^{-6}$ & foxes & foxes & pituitary & Morn2 & -0.25 & 0.05 & [23] \\
\hline 27 & Morn1 & 1.24 & $10^{-6}$ & guinea pigs & cavy & frontal cortex & Morn2 & 0.89 & 0.05 & [25] \\
\hline 28 & Mre11a & -2.47 & $10^{-3}$ & guinea pigs & cavy & frontal cortex & Mre11a & 1.42 & $10^{-4}$ & [25] \\
\hline 29 & $N r 4 a 3$ & -1.29 & $10^{-4}$ & chicken & chicken & pituitary & $N r 4 a 3$ & -0.85 & 0.05 & [29] \\
\hline 30 & $N r 4 a 3$ & -1.29 & $10^{-4}$ & rabbits & rabbits & amygdala & $N r 4 a 3$ & -1.58 & 0.05 & [28] \\
\hline 31 & $N r 4 a 3$ & -1.29 & $10^{-4}$ & guinea pigs & cavy & frontal cortex & $N r 2 c 1$ & -0.74 & $10^{-2}$ & [25] \\
\hline 32 & $N r 4 a 3$ & -1.29 & $10^{-4}$ & chicken & chicken & pituitary & $N r 3 c 1$ & 0.51 & $10^{-5}$ & [29] \\
\hline 33 & $N r 4 a 3$ & -1.29 & $10^{-4}$ & guinea pigs & cavy & frontal cortex & $N r 5 a 1$ & -2.19 & 0.05 & [25] \\
\hline 34 & Orai1 & 1.83 & 0.05 & guinea pigs & cavy & frontal cortex & Orai1 & -1.30 & $10^{-3}$ & {$[25]$} \\
\hline 35 & $P 2 r x 4$ & 1.14 & 0.05 & guinea pigs & cavy & frontal cortex & $P 2 r x 6$ & 0.55 & 0.05 & [25] \\
\hline 36 & Pcdhb9 & -1.01 & $0.05^{4}$ & guinea pigs & cavy & frontal cortex & Pcdh20 & -0.73 & 0.05 & [25] \\
\hline 37 & Pcdhb9 & -1.01 & $0.05^{4}$ & guinea pigs & cavy & frontal cortex & Pcdhac1 & 0.72 & $10^{-2}$ & [25] \\
\hline 38 & Pcdhb9 & -1.01 & $0.05^{4}$ & rabbits & rabbits & $\begin{array}{l}\text { parietal-temporal } \\
\text { cortex }\end{array}$ & Pcdhb15 & -1.04 & 0.05 & [28] \\
\hline 39 & Pcdhb9 & -1.01 & $0.05^{4}$ & rats & rats & frontal cortex & Pcdhga1 & 2.10 & $10^{-5}$ & [25] \\
\hline 40 & Pcdhb9 & -1.01 & $0.05^{4}$ & rabbits & rabbits & amygdala & Pcdhgb4 & 1.53 & $10^{-4}$ & [28] \\
\hline 41 & Pcdhb9 & -1.01 & $0.05^{4}$ & rabbits & rabbits & $\begin{array}{l}\text { parietal-temporal } \\
\text { cortex }\end{array}$ & Pcdhgb4 & 1.06 & $10^{-4}$ & {$[28]$} \\
\hline 42 & Pcdhb9 & -1.01 & $0.05^{4}$ & rabbits & rabbits & hypothalamus & Pcdhgb4 & 1.67 & $10^{-2}$ & [28] \\
\hline 43 & Pla $2 g 2 c$ & -1.08 & 0.05 & rabbits & rabbits & $\begin{array}{l}\text { parietal-temporal } \\
\text { cortex }\end{array}$ & Pla1a & 1.35 & $10^{-2}$ & [28] \\
\hline 44 & Pla2g2c & -1.08 & 0.05 & guinea pigs & cavy & frontal cortex & Pla2g $4 a$ & -1.74 & $10^{-7}$ & {$[25]$} \\
\hline 45 & Pla2g2c & -1.08 & 0.05 & rabbits & rabbits & $\begin{array}{l}\text { parietal-temporal } \\
\text { cortex }\end{array}$ & Pla2g $4 c$ & 2.29 & $10^{-8}$ & [28] \\
\hline 46 & Pla2g2c & -1.08 & 0.05 & rabbits & rabbits & amygdala & Pla $2 g 4 c$ & 2.34 & $10^{-3}$ & [28] \\
\hline 47 & Pla2g2c & -1.08 & 0.05 & rabbits & rabbits & hippocampus & Pla2g $4 c$ & 1.63 & 0.05 & [28] \\
\hline 48 & Pla2g $2 c$ & -1.08 & 0.05 & guinea pigs & cavy & frontal cortex & Pla2g5 & -1.01 & 0.05 & [25] \\
\hline 49 & Pla2g2c & -1.08 & 0.05 & chicken & chicken & pituitary & Pla $2 g 7$ & -0.83 & $10^{-2}$ & [29] \\
\hline 50 & $R b m 3$ & 1.04 & $10^{-3}$ & guinea pigs & cavy & frontal cortex & $R b m 11$ & 1.02 & 0.05 & [25] \\
\hline 51 & Sh3bgr & 1.11 & 0.05 & guinea pigs & cavy & frontal cortex & Sh3bgr & 0.99 & $10^{-2}$ & [25] \\
\hline 52 & Shox 2 & 6.18 & 0.05 & rabbits & rabbits & hippocampus & Shox 2 & -3.43 & $10^{-3}$ & [28] \\
\hline 53 & Spint1 & -0.91 & 0.05 & dogs & wolves & blood & Spint1 & 5.28 & $10^{-2}$ & {$[24]$} \\
\hline 54 & Tpm2 & 1.44 & $10^{-2}$ & foxes & foxes & pituitary & Tpm4 & 0.84 & $10^{-8}$ & [23] \\
\hline
\end{tabular}

Following our previous article [36] on a factor analysis of qPCR-identified DEGs within in the hypothalamus of tame versus aggressive rats [34], in this work, we processed Table 6 by principal component analysis (Figure 1: STEP 2), the results of which are presented in Figure 3. In this figure, one can see that the first (main) principal component PC1 (X-axis) is proportional to arithmetic means of the log2 values measured by independent experiments on domestic animals compared with their wild congeners. PC1 
explains two-thirds (67\%) of differential-gene-expression variance under study. This is parallel to the dotted line (Figure 3) along which all orthologs (Banp, Cd22, Nr4a3, and $H b b-b 1)$ with multiple homologs are located. Indeed, two Banp-related orthologous gene pairs (\#1 and \#2) supported one another in homology, as did two Cd22-related gene pairs (\#3 and \#4). Additionally, two Nr4a3-related gene pairs (\#29 and \#30) were supported by their paralogs (rows \#\# 31-33), as was the Hbb-b1-related pair (\#10); it is supported by its paralogs in rows \#\# 11-14. Additionally, the second (minor) principal component, PC2 (Figure 3: $Y$-axis), is proportional to the difference between the estimates determined by the measurement in this work and corresponding estimates obtained independently by others. PC2 explains one-third (33\%) of differential-gene-expression variance under study. It is parallel to the dashed line, where all single orthologs (Eif2b3, Ghitm, Mre11a, Orai1, Sh3bgr, Shox2, and Spint1) are located (Table 6: rows \#\# 6, 9, 28, 34, 51, and 52, respectively).

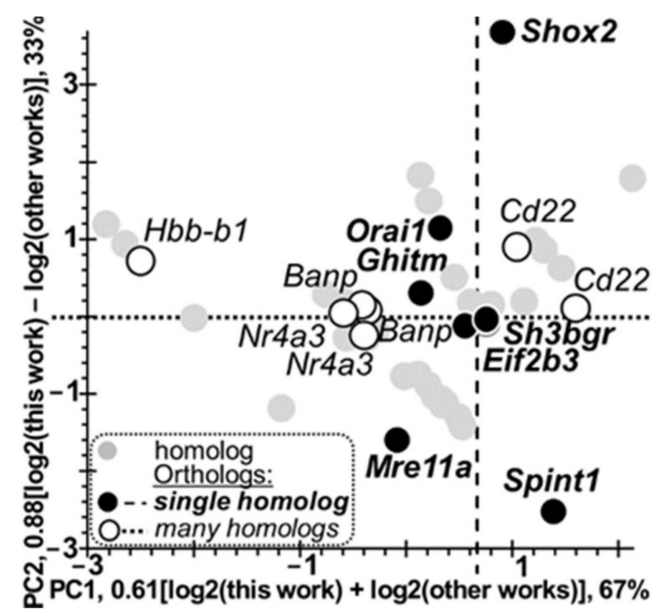

Figure 3. The results of principal component analysis of the hypothalamic DEGs of tame versus aggressive rats found in this work in comparison with their known homologous DEGs in domestic animals versus their wild congeners as reported by others. Legend: see the footnote of Table 4 and legend of Figure 1; open circles: all seven single orthologs Eif2b3 (Table 6: row \#6), Ghitm (\#9), Mre11a (\#28), Orai1 (\#34), Sh3bgr (\#51), Shox2 (\#52), and Spint1 (\#53) grouped along a dashed line; filled circles: all seven orthologs supported by other homologs Banp (\#1 and \#2, which support one another in homology), Cd22 (\#3 and \#4 supporting each other in homology), Nr4a3 (\#29 and \#30 supported one another in homology as well as by their paralogs in rows \#\# 31-33), and Hbb-b1 (\#10 supported by its paralogs in rows \#\# 11-14) grouped along a dotted line; grey circles: all the remaining homologs; $\log 2$ (this work) and $\log 2$ (other works) correspond to columns iii and ix of Table 6; PC1 and PC2: first (major) and second (minor) principal components calculated by means of software package Statistica (Statsoft ${ }^{\mathrm{TM}}$, Tulsa, OK, USA); they are parallel to the dotted and dashed lines, respectively.

After that, keeping the two pairs of parallel lines in Figure 3 in mind (i.e., PC1 and the dotted line fitting orthologous DEGs with multiple homologs as well as PC2 and the dashed line fitting single orthologous DEGs), we performed a statistical analysis of the binary correlation between either multiple-homolog orthologous DEGs or single orthologous DEGs, namely, we tested whether there are the same or opposite signs of the log2 value within an orthologous DEG pair being tested (Figure 1: STEP 3).

To this end, we first formatted standard Fisher's $2 \times 2$ table for binary correlation tests and then performed Fisher's exact test, Pearson's $\chi^{2}$ test, and binomial distribution analysis using the standard software, Statistica (Statsoft ${ }^{\mathrm{TM}}$, Tulsa, OK, USA), as shown in Table 7. Within columns iii and iv of this table, readers can see that all the seven orthologous DEG pairs supported by multiple homologs have the same sign, in contrast to most of single orthologous DEG pairs (five of seven), which have opposite signs. This difference between single orthologous DEGs and those supported by multiple homologs is statistically significant according to Pearson's $\chi^{2}$ test and Fisher's exact test, as shown in 
columns vii and $\mathrm{v}$ of Table 7 , respectively. Moreover, according to binomial distribution analysis (column $\mathrm{v}$ of Table 7), the orthologous DEG pairs supported by multiple homologs statistically significantly keep the sign of the $\log 2$ value in independent experiments on domestic versus wild animals $\left(p<10^{-3}\right)$, whereas single orthologous DEGs are statistically insignificant in this regard $(p>0.2)$. Thus, the set of the DEGs identified by other authors in their experiments on domestic versus wild animals (Table 2) contains at least two biologically different subsets, namely: (a) PC1-linked orthologous DEGs supported by multiple homologs and (b) PC2-linked single orthologous DEGs.

Table 7. Correlations between the significant differential gene expression in the tame versus aggressive rats under study and significant differential gene expression in domestic animals versus their wild congers presented in Table 6.

\begin{tabular}{|c|c|c|c|c|c|c|c|}
\hline \multirow[b]{2}{*}{ Homology Type } & \multirow[t]{2}{*}{ log2 Value } & \multicolumn{2}{|c|}{ Signs of Log2 Values of Homologous DEGs } & \multirow{2}{*}{$\begin{array}{c}\text { Binomial } \\
\text { Distribution }\end{array}$} & \multicolumn{2}{|c|}{$\chi^{2}$ Test } & \multirow{2}{*}{$\begin{array}{l}\text { Fisher's } \\
\text { Exact Test }\end{array}$} \\
\hline & & $\begin{array}{c}\text { PC1: } \\
\text { Same Signs }\end{array}$ & $\begin{array}{c}\text { PC2: } \\
\text { Opposite Signs }\end{array}$ & & $x^{2}$ & $p$ & \\
\hline i & ii & iii & iv & $\mathbf{v}$ & vi & vii & viii \\
\hline $\begin{array}{c}\text { Number of Orthologous } \\
\text { DEG Pairs }\end{array}$ & $\begin{array}{l}\text { Many Homologs } \\
\text { Only One Gene }\end{array}$ & $\begin{array}{l}7 \\
2\end{array}$ & $\begin{array}{l}0 \\
5\end{array}$ & $\begin{array}{l}10^{-3} \\
0.23\end{array}$ & 7.78 & $10^{-2}$ & 0.05 \\
\hline
\end{tabular}

Therefore, we finally performed a correlation analysis on the DEGs found in this work (in the hypothalamus of tame versus aggressive rats) with respect to both the PC1- and PC2-linked orthologous DEGs mentioned above (Figure 1: STEP 4) independently from one another, as readers can see in Figure 4a,b, respectively. As shown in Figure 4a, according to four statistical criteria-i.e., Pearson's linear correlation (r), the Goodman-Kruskal generalized correlation $(\gamma)$, and Spearman's $(R)$ and Kendall's $(\tau)$ rank correlations-there are statistically significant positive correlations between the log2 values of DEGs in the hypothalamus of tame versus aggressive rats ( $X$-axis; column iii of Table 6) [this work] and the $\log 2$ values of their orthologous DEGs (in domestic versus wild animals as measured by others: Y-axis; column ix of Table 6) supported by multiple homologs (i.e., PC1-linked).

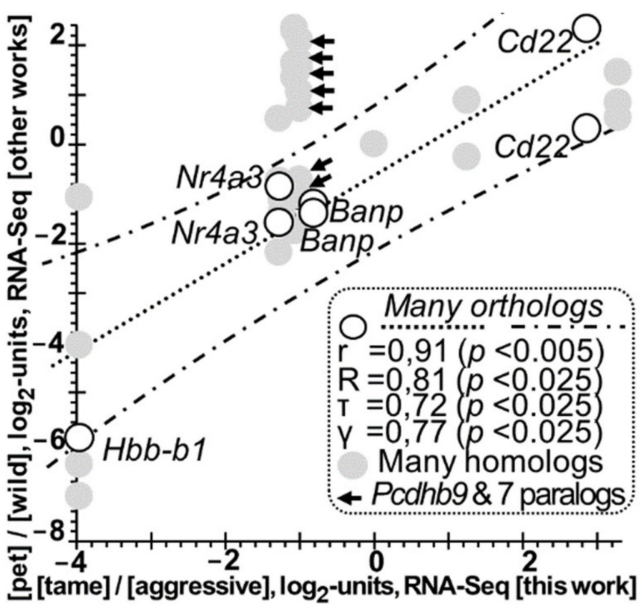

(a)

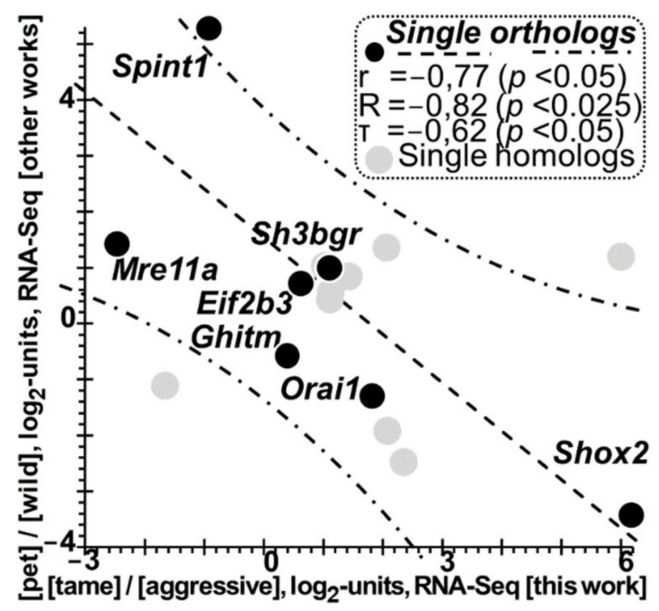

(b)

Figure 4. Statistically significant correlations between the $\log 2$ values of DEGs in the hypothalamus of tame vs. aggressive rats as measured in this work (X-axis; column iii of Table 6) and the $\log 2$ values of their known orthologous DEGs in domestic vs. wild animals as measured by others ( $Y$-axis; column ix of Table 6). Legend: see legends of Figures 2 and 3; (a) PC1-linked orthologous DEGs supported by multiple homologs; arrows $(\rightarrow)$ point to Pcdhb9 compared with its seven paralogs (rows \#\# 36-42 of Table 6); (b) PC2-linked single orthologous DEGs.

Moreover, gray circles in this figure show similar pairs formed by DEGs identified here and their homologous DEGs identified by others and supported by multiple homologs 
(i.e., PC1-linked too). These circles fit reasonably well into the $95 \%$ confidence interval (between two dash-and-dot lines) of the linear correlation presented (a dotted line).

In Figure 4a, arrows point to the rat gene Pcdhb9 compared with its seven paralogs (rows \#\# 36-42 of Table 6), where two of these seven pairs fit within the $95 \%$ confidence interval (rows \#\# 36 and 38 in Table 6), while five remaining pairs fall outside this interval. Because the paralogous genes are homologs that arose via a duplication of their common ancestral gene and next via divergence in their biological functions, the observed partial deviation of these paralogous pairs from the common pattern of the genes-orthologs keeping functions from species to species looks expected rather than unexpected.

All these robust correlations taken together allow us for the first time to identify common orthologous DEGs of various domestic animals (versus their wild congeners) that from species to species and from tissue to tissue, statistically significantly keep the sign of the $\log 2$ value in line with principal component 1 of this domestication-related differential gene expression. PC1 explains two-thirds (67\%) of this expression pattern variance (Figures 3 and 4a). This finding may reflect the most common pattern of animal domestication.

Finally, Figure $4 \mathrm{~b}$ presents significant negative correlations between the $\log 2$ values measured in this work (X-axis; column iii of Table 6 ) and those measured in experiments by others in domestic versus wild animals ( $Y$-axis; column ix of Table 6$)$ in the case of the PC2linked single orthologous DEGs; these correlations are statistically significant according to Pearson's linear correlation ( $r$ ) and Spearman's $(R)$ and Kendall's $(\tau)$ rank correlation analyses. In addition, gray circles depict similar single pairs of DEGs identified here with their homologous DEGs identified elsewhere (i.e., PC2-linked too) that fit reasonably well between two dash-and-dot lines, where the $95 \%$ confidence interval covers the linear correlation examined (a dotted line). Altogether, this robust evidence for the first time shows that some unique orthologous DEGs of various domestic versus wild animals can statistically significantly reverse the $\log 2$ value sign in agreement with the principal component (PC2) explaining one-third (33\%) of this domestication-related differentialgene-expression variance (Figures 3 and $4 \mathrm{~b}$ ). Indeed, this is exactly what we have already seen in both qPCR and the maximum-variation (maxVar) factor analysis [35], namely: two factors of the differential gene expression (in tame versus aggressive rats) that explain $67 \%$ of its variance: behavioral selection and laboratory lifestyle (i.e., domestication), while the remaining $33 \%$ of the variance can be explained by intraspecific variation [35]. Therefore, here the second principal component (PC2) explaining $33 \%$ of the differential gene expression variance between domestic and wild animals (Figures 3 and $4 \mathrm{~b}$ ) reflects both interspecific variation and intraspecific variation and is close to the gold standard of variation in nature.

Thus, here we for the first time simultaneously quantified two independent phenomena —domestication [1] and cladogenesis [6] —at the same scale (genome-wide analysis). These phenomena respectively explained two-thirds and one-third of differential-geneexpression variance between domestic and wild animals as responses of their genomes to effects of artificial and natural environments. Nevertheless, it seems that the elucidation of the influence of both interspecific and intraspecific variation on the process of domestication of animals by humans requires further research, which is outside the scope of this work.

\section{Discussion}

Let us discuss biomedical applications of the results, keeping in mind that the mainstream in genome-wide studies on domestic versus wild animals is the search for speciesspecific DEGs [23-29]. There is an exception where investigators introduced the new biomedical concept of self-domestication syndrome [30], although the idea of human selfdomestication is still debatable [31]. An algorithmic flowchart illustrating the biomedical application of our results to the search for human candidate genes contributing to selfdomestication syndrome is presented in Figure 5. As readers can see in this figure, the test 
data under study included the 54 homologous DEG pairs of domestic versus wild animals

(Table 6), where the total number of animal genes is 79.

\section{TEST DATA:}

\section{DEGs of domestic versus wild animals under this study}

\section{STEP 1: COMPARATIVE ANALYSIS}

search for DEGs (of domestic vs wild animals) that are homologs of the human genes under study

79 DEGs of domestic vs wild animals

14 homologous pairs

\begin{tabular}{|c|c|c|c|c|c|}
\hline \multicolumn{4}{|c|}{ Human } & \multicolumn{2}{|r|}{ Animals } \\
\hline \multirow{2}{*}{ Gene } & \multicolumn{3}{|c|}{$\begin{array}{l}\text { Gene expression change can both decrease }(\rightarrow) \text { and } \\
\text { increase }(\leftarrow) \text { the human reproductive potential }(\$)\end{array}$} & RNA-Seq & $\begin{array}{l}\text { Gene expression changes durin } \\
\text { from nearest common a }\end{array}$ \\
\hline & \multirow{4}{*}{$\begin{array}{c}\text { deficit }(\downarrow) \\
\text { low hemoglobin } \\
\text { (thalassemia) elevates risks } \\
\text { of auto-aggressive } \\
\text { impulsiveness up to suicide }\end{array}$} & \multirow{4}{*}{\multicolumn{2}{|c|}{$\begin{array}{l}\text { excess ( } \uparrow \text { ) } \\
\text { eliteathletes do high-altitude } \\
\text { trains rising hemoglobin level } \\
\text { beforelow-altitude matches } \\
\text { that risestheirwinchances }\end{array}$}} & DEG $\log 2$ & deficit $(\downarrow)$ \\
\hline \multirow{3}{*}{$H B D$} & & & & $H b b-b 1-3.97$ & tame rats \\
\hline & & & & Hbad -1.07 & domestic chicken \\
\hline & & & & $H b z 1-7.10$ & dogs \\
\hline \multirow{3}{*}{\multicolumn{4}{|c|}{$\begin{array}{cc}\text { hyper-anxiety in impaired } \\
\text { NR5A1 aggressive sexual behavior } \rightarrow \\
\text { up to infertility }\end{array} \begin{array}{c}\text { estrogen excess as a risk } \\
\text { factor of endometriosis } \\
\text { and others estrogen- } \\
\text { dependent inflammations }\end{array} \rightarrow$}} & $\mathrm{Nr} 4 a 3-1.29$ & tame rats \\
\hline & & & & $N r 3 c 1 \quad 3.51$ & wild chicken \\
\hline & & & & Nr5a1 -2.19 & guine: \\
\hline \multicolumn{4}{|c|}{$\begin{array}{ccc}\text { short stature is a well- } \\
\text { SHOX } \\
\text { known adaptive response } \\
\text { to } \leftarrow \text { adverse life conditions }\end{array} \quad \begin{array}{c}\text { tall stature aggravates } \\
\text { pregnancy in military } \\
\text { active-duty women }\end{array}$} & $\begin{array}{lc}\text { Shox2 } & 6.18 \\
\text { Shox2 } & -3.43\end{array}$ & $\begin{array}{l}\text { aggressive rats } \\
\text { domestic rabbits }\end{array}$ \\
\hline \multicolumn{6}{|c|}{$\begin{array}{l}\text { STEP 2: STATISTICALANALYSIS } \\
\text { formatting Fisher's binary correlation table } 2 \times 2 \text { and, next, checking Fisher's exact test, Pearso } \\
\text { and binomial distribution using the standard software STATISTICA (Statsoft }{ }^{\mathrm{TM}}, \text { Tulsa, OK, U }\end{array}$} \\
\hline & & HUMAN & & PRODUCTIVE & POTENTIAL \\
\hline & ANIMALS & & DECR & EASED & INCREA SED \\
\hline & & DOMESTIC & NDOMESCTIC & C; DECREASE D & NDOM ESCTIC; INCRE SED \\
\hline & & WILD & NWILD; D & ECREASED & NWILD; INCRE SED \\
\hline
\end{tabular}

Figure 5. An algorithmic flowchart depicting biomedical application of our results to the search for human candidate genes contributing to self-domestication syndrome. Legend: see the footnotes of Tables 4 and 6 as well as legends of Figures 1-3.

Additionally, we took into account all the 68 human genes whose effects on human reproductive potential (as the most common index of how many chances humans have to survive, have children, and help them become the next generation under the best conditions $[53,54]$ ) have previously been estimated elsewhere $[55,56]$ by means of SNPs within human gene promoters. In the present study, we updated these estimates in line with the current state of PubMed [52], as shown in Table S2.

First of all, using the above-mentioned test data, we compiled all possible (14) pairs of the human genes together with their homologous genes in animals, as depicted by a Venn diagram in Figure 5 (STEP 1). Table 8 presents these pairs of homologous human versus 
animal genes as follows: the left half of this table (i.e., columns $i$ to $v$ ) is a copy of the data on a human gene in question from Table S2, whereas the right half (i.e., columns vi, vii, and $\mathrm{x}$ ) is a copy of the RNA-Seq data on the corresponding homologous DEG in domestic versus wild animals (Table 6).

Furthermore, columns viii and ix of Table 8 translate a $\log 2$ value of a gene in an animal into either low or excessive expression of this gene during divergence of both domestic and wild forms of this animal from their most recent common ancestor. Recently [57,58], an RNA-Seq data analysis was based on this oldest phylogeny concept [59] widely used elsewhere [60-63]. Let us look at these orthologous genes one by one and discuss effects of their expression changes on reproductive potential in humans as well as during divergence of domestic and wild animals from their most recent com-mon ancestor $[24,25,28,29,64-86]$ (Table 8).

Human gene $H B D$ produces hemoglobin subunit $\delta$, a deficit of which (thalassemia) is clinically proven as a risk factor for auto-aggressive impulsiveness up to suicide [64], female subfertility [65], under-threshold IQ, and severe anxiety in children [66], as readers can see in Table 8. Actually, both suicide and IQ look like human-specific traits, which are biomedically studied mostly in human behavioral models based on animals $[67,68]$ and are not common in the wild [56]. Curiously, anxiety is the most important trait for mutual trust within a human-pet pair, as independently discovered for dogs [69], sheep [70], and guinea pigs [71]. Moreover, according to a sports medicine report [72], combat success of healthy young boxers, kick boxers, and karate fighters increases with an increase in their anxiety in the arena (this anxiety prevents injuries until the end of a fight or sparring).

Finally, via Stroop-like interference effect approximation [73], Nobel laureate Daniel Kahneman [74] highlighted anxiety among pivotal factors for human economic decision making during exposure to both psychological and social stressors. As shown in Table 8, a human hemoglobin deficit is consistent with that in tame rats [75], dogs [24], and domestic chickens [29] during their divergence from the most recent common ancestors along with their wild congeners (column viii) according to their negative log2 values (column vii).

As for human hemoglobin overexpression, according to a cohort-based study [76], elite athletes do high-altitude training raising the hemoglobin level before low-altitude matches thereby increasing their chances of winning. Thus, humans' chances for success increase with a small subcritical increase in their hemoglobin level, consistently with a hemoglobin excess in aggressive rats [75], wolves [24], and wild chickens [29] during their microevolution (Table 8: column ix) according to their positive log2 values (Table 8: column vii). Altogether, readers can see in row \#1 of Table 8 that animal genes that are homologs of the human $H B D$ gene, from species to species are underexpressed in domestic animals and overexpressed in their wild congeners with respect to their most recent common ancestors.

This finding fits the first principal component (PC1) explaining two-thirds $(67 \%)$ of the differential-gene-expression variance during the domestication-related microevolution (Figures 3 and $4 a$ ). With this in mind, we suggest $H B D$ as a candidate gene contributing to self-domestication syndrome, namely: low HBD expression might be regarded as what humans pay with health (e.g., higher risks of suicide [64], female subfertility [65], low IQ, and anxiety in children [66]) for the benefits received during evolution (e.g., the ability to build trust [69-71], prevention of injuries [72], and making adequate decisions under stress [74]).

Human gene NR5A1 encodes steroidogenic factor 1, both a deficit and excess of which reduce human reproductive potential on the one hand via hyper-anxiety during impaired aggressive sexual behavior up to male infertility [77] as well as hypoestrogenism [78] leading to $1 \%$ of cases of female infertility [79], and on the other hand, hyperestrogenism elevates risks of endometriosis and others estrogen-dependent inflammatory disorders in women [80,81]. That is why both domestic and wild forms of rats [82], chickens [29], rabbits [28], and guinea pigs [25] could have paid with their health (i.e., hormonal dysregulation) for the benefits that each of them got during microevolution (Table 8). Thus, we have no idea whether NR5A1 has something to do with self-domestication syndrome. 


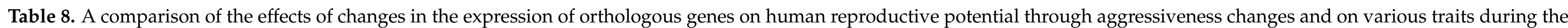
divergence of domestic animals and their wild congeners from the corresponding most recent common ancestor.

\begin{tabular}{|c|c|c|c|c|c|c|c|c|c|}
\hline \multicolumn{5}{|c|}{ Humans } & \multicolumn{5}{|c|}{ Animals } \\
\hline \multirow[t]{2}{*}{ Gene } & \multicolumn{4}{|c|}{$\begin{array}{l}\text { Effect of Gene Expression Changes on Human Reproductive Potential, Namely (\$): Decreased } \\
\qquad(\rightarrow) \text { or Increased }(\leftarrow)\end{array}$} & \multicolumn{2}{|c|}{ RNA-Seq } & \multicolumn{2}{|c|}{$\begin{array}{l}\text { Effect of Gene Expression Changes } \\
\text { during DIVERGENCE from the most } \\
\text { Recent Common Ancestor }\end{array}$} & \multirow[t]{2}{*}{ [Ref } \\
\hline & Deficit $(\downarrow)$ & $\$$ & Excess $(\uparrow)$ & $\$$ & $D E G$ & $\log 2$ & Deficit $(\downarrow)$ & Excess $(\uparrow)$ & \\
\hline i & ii & iii & iv & $\mathbf{v}$ & vi & vii & viii & ix & $\mathbf{x}$ \\
\hline$H B D$ & $\begin{array}{c}\text { hemoglobin deficit (thalassemia) elevates } \\
\text { risks of auto-aggressive impulsiveness up to } \\
\text { suicide [64], female subfertility [65], causes } \\
\text { under-threshold IQ and severe anxiety in } \\
\text { children [66] }\end{array}$ & $\rightarrow$ & $\begin{array}{l}\text { in cohort studies: elite athletes do } \\
\text { high-altitude training rising hemoglobin } \\
\text { level before low-altitude matches thereby } \\
\text { increasing their chances of winning [76] }\end{array}$ & $\leftarrow$ & $\begin{array}{l}H b b-b 1 \\
H b b l \\
H b a 1 \\
H b a d \\
H b m \\
H b z 1\end{array}$ & $\begin{array}{l}-3.97 \\
-5.92 \\
-4.06 \\
-1.07 \\
-6.46 \\
-7.10\end{array}$ & $\begin{array}{c}\text { tame rat } \\
\text { dogs } \\
\text { dogs } \\
\text { domestic chicken } \\
\text { dogs } \\
\text { dogs }\end{array}$ & $\begin{array}{l}\text { aggressive rat } \\
\text { wolves } \\
\text { wolves } \\
\text { wild chicken } \\
\text { wolves } \\
\text { wolves }\end{array}$ & $\begin{array}{l}{[75]} \\
{[24]} \\
{[24]} \\
{[29]} \\
{[24]} \\
{[24]}\end{array}$ \\
\hline \multirow{6}{*}{ NR5A1 } & \multirow{6}{*}{$\begin{array}{l}\text { within human disease models based on } \\
\text { Nr5a1-null male mice: hyper-anxiety during } \\
\text { impaired aggressive sexual behavior up to } \\
\text { male infertility in line with male patients } \\
\text { carrying NR5A1 defects [77] as well as } \\
\text { NR5A1 deficit can cause hypoestrogenism } \\
\text { [78] leading to } 1 \% \text { of cases of female } \\
\text { infertility [79] }\end{array}$} & \multirow{6}{*}{$\rightarrow$} & \multirow{6}{*}{$\begin{array}{l}\text { in retrospective meta-analysis of PubMed } \\
\text { content: NR5A1 excess contributes to } \\
\text { excessive estrogen biosynthesis raising risks } \\
\text { of estrogen-dependent inflammatory } \\
\text { disorders in women [80] and vice versa for } \\
\text { men [81] }\end{array}$} & \multirow{6}{*}{$\rightarrow$} & $N r 4 a 3$ & $-1,29$ & tame rat & aggressive rat & [82] \\
\hline & & & & & $N r 4 a 3$ & -0.85 & domestic chicken & wild chicken & [29] \\
\hline & & & & & $N r 4 a 3$ & -1.58 & domestic rabbits & wild rabbits & {$[28]$} \\
\hline & & & & & $N r 2 c 1$ & -0.74 & guinea pigs & cavy & [25] \\
\hline & & & & & $N r 3 c 1$ & 0.51 & wild chicken & domestic chicken & [29] \\
\hline & & & & & Nr5a1 & -2.19 & guinea pigs & cavy & {$[25]$} \\
\hline SHOX & $\begin{array}{c}\text { in cohort studies: low SHOX expression } \\
\text { causes short stature [83] as adaptive } \\
\text { epigenetic response to adverse living } \\
\text { conditions, when each calorie saved due to } \\
\text { short stature helps to enhance stress } \\
\text { resistance [84] }\end{array}$ & $\leftarrow$ & $\begin{array}{l}\text { in cohort studies: girls carrying one extra } \\
\text { SHOX copy have tall stature [85] elevating } \\
\text { risks of pregnancy complications in military } \\
\text { active-duty women [86] }\end{array}$ & $\rightarrow$ & Shox2 & -3.43 & domestic rabbits & wild rabbits & [87] \\
\hline
\end{tabular}


Human gene SHOX (short stature homeobox) underexpression is an adaptive epigenetic response to adverse living conditions in humans according to a cohort-based study [83] because each calorie saved due to short stature helps to enhance stress resistance [84]. This SHOX insufficiency in humans corresponds to a Shox2 deficit [87] in aggressive rats under study. Nonetheless, in another cohort-based study [85], researchers analyzed girls carrying one extra SHOX copy manifesting in tall stature, which is a risk factor for pregnancy complications in military active-duty women [86]. As readers can see in Tables 4, 6, and 8, within the framework of our study, the human SHOX overexpression matches Shox 2 overexpression [87] in tame rats. Let us recall Figures 3 and $4 b$, where the animal Shox 2 gene was seen within only a single orthologous pair of genes carrying opposite signs of $\log 2$ values compared with each other, in accordance with the second principal component (PC2) explaining one-third (33\%) of the differential-gene-expression variance during domestication. Therefore, in contrast to tame rats, domestic rabbits seem to do well with short stature [83] because they could be anthropogenically artificially selected for the purpose of increasing their fertility for meat production, despite the tall-stature-related complications of pregnancy $[85,86]$, as shown in the last row of Table 8 . With this in mind, we would link the second principal component illustrated here by the animal Shox 2 gene (Figures 3 and $4 \mathrm{~b}$ ) to both interspecific and intraspecific variation.

Altogether, here we propose SHOX as a candidate human gene contributing to selfdomestication syndrome as follows: SHOX excess as an epigenetic response to better life [84] resulting in tall stature [83] might be regarded as what humans pay with health (e.g., the tall-stature-related complications of pregnancy $[85,86]$ ) for the benefits received during evolution (e.g., the anthropogenic environment instead of the natural one).

Table 9 is standard Fisher's $2 \times 2$ table that summarizes the findings of the comparative analysis of the above-mentioned similar genes of humans and animals (columns iii and iv) and presents the results of statistical analysis of these data, as shown in Figure 5 (STEP 2). As evident here, 13 and one of these domestic-animal DEGs correspond to human genesmarkers of a decrease and increase in human reproductive potential, while the same is true for seven and seven DEGs in the wild animals.

Table 9. Correlations between the effects of co-directed changes in the expression of homologous genes on the human reproductive potential and on various traits during the divergence of the domestic and wild animals from their most recent common ancestor.

\begin{tabular}{|c|c|c|c|c|c|c|c|}
\hline \multirow[b]{2}{*}{ Animals } & \multirow[t]{2}{*}{ Human } & \multicolumn{2}{|c|}{$\begin{array}{l}\text { Effect of Gene Expression Changes } \\
\text { on Human Reproductive Potential }\end{array}$} & \multirow{2}{*}{$\begin{array}{c}\text { Binomial } \\
\text { Distribution }\end{array}$} & \multicolumn{2}{|c|}{$\begin{array}{l}\text { Pearson's } \\
\chi^{2}-\text { Test }\end{array}$} & \multirow{2}{*}{$\begin{array}{l}\text { Fisher's } \\
\text { Exact Test }\end{array}$} \\
\hline & & Decreased $(\rightarrow)$ & Increased $(\leftarrow)$ & & $x^{2}$ & $p$ & \\
\hline $\mathbf{i}$ & ii & iii & iv & $\mathbf{v}$ & vii & viii & ix \\
\hline $\begin{array}{l}\text { Gene Expression Changes During } \\
\text { Divergence from Most Recent } \\
\text { Common Ancestor }\end{array}$ & $\begin{array}{l}\text { domestic } \\
\text { wild }\end{array}$ & $\begin{array}{l}13 \\
7\end{array}$ & $\begin{array}{l}1 \\
7\end{array}$ & $\begin{array}{l}10^{-3} \\
0.60\end{array}$ & 6.30 & 0.05 & 0.05 \\
\hline
\end{tabular}

Therefore, one can see that the DEGs in domestic animals statistically significantly match their human orthologous genes aggravating human diseases according to Pearson's $\chi^{2}$ test $(p<0.05)$, Fisher's exact test $(p<0.05)$, and binomial distribution analysis $(p<0.001)$. Finally, the last row of this table illustrates that DEGs of wild animals correspond to a set of human orthologous genes where some genes weaken while others improve human reproductive potential ( $p>0.5$, binomial distribution), overall corresponding to a norm (i.e., the wild type). Thus, the artificial environment of domestic animals alters the activity of their genes in the same direction as that seen in the corresponding human genes during some human diseases, whereas the natural environment maintains a normal gene expression pattern in wild animals (corresponding to health in humans). 


\section{Conclusions}

First, in this study, we sequenced the hypothalamus transcriptome of tame and aggressive adult male rats and deposited these primary experimental data in the NCBI SRA database [40] (ID = PRJNA668014), where they are freely available for those who would like to use them in the future.

Second, in these data, we identified 46 DEGs (in the hypothalamus of the tame versus aggressive rats under study) that were statistically significant $\left(\mathrm{P}_{\mathrm{ADJ}}<0.05\right.$, according to correction for multiple comparisons). We selectively verified the reproducibility of these DEGs in another qPCR experiment on an independent set of biological samples.

Third, using principal component analysis, we for the first time compared the 46 hypothalamic DEGs of tame versus aggressive rats found here with 2347 DEGs of domestic versus wild animals found by others. This analysis yielded two principal components, PC1 and $\mathrm{PC} 2$, respectively explaining $67 \%$ and $33 \%$ of the differential-gene-expression variance between all the domestic and wild animals under study. In this way, we showed that PC1 corresponds mostly the orthologous DEGs supported by multiple homologs, which often kept the sign of their $\log 2$ values from species to species and from tissue to tissue as the common pattern of animal domestication. On the contrary, PC2 corresponds to the single orthologous DEGs without homologous supporting genes; these DEGs mainly reversed the sign of their $\log 2$ values from one species to another and from tissue to tissue; thus, PC2 may reflect both intraspecific and interspecific variation of gene expression alterations during domestication. This allows us to conclude that domestication explains two-thirds of differential-gene-expression variance between domestic and wild animals (i.e., PC1), whereas the remaining one-third reflects intraspecific and interspecific variation (i.e., PC2).

Supplementary Materials: The following are available online at https: / www.mdpi.com/article / 10.3390 /ani11092667/s1, Table S1. Statistically significant correlations between the relative expression levels of the seven differentially expressed genes (DEGs) and one reference genes within the hypothalamus of tame versus aggressive rats, which were measured experimentally in vivo using RNA-Seq [this work] and qPCR [34] methods. Table S2. Effects of underexpression or overexpression of the human genes under this study on the human diseases through aggressiveness changes, as estimated [56,57].

Author Contributions: Conceptualization and supervision, N.A.K.; methodology, A.M.; investigation, I.C., R.K., N.K. and S.S.; software, A.B.; validation, L.S. and P.P.; resources, D.O.; data curation, V.S.; writing - original draft preparation, M.P. All authors have read and agreed to the published version of the manuscript.

Funding: This study was supported by the Russian Science Foundation (grant No. 19-74-10041).

Institutional Review Board Statement: This study was conducted according to the guidelines of the Declaration of Helsinki, Directive 2010/63/EU of the European Parliament and of the European Council of 22 September 2010. The research protocol was approved by the Interinstitutional Commission on Bioethics at the Institute of Cytology and Genetics SB RAS, Novosibirsk, Russia (Approval documentation No. 8 dated 19 March 2012).

Informed Consent Statement: Not applicable.

Data Availability Statement: The primary RNA-Seq data obtained in this work were deposited in the NCBI SRA database (ID = PRJNA668014).

Acknowledgments: We are grateful to Nikolai Shevchuk (Shevchuk Editing Co., Brooklyn, NY, USA) for fruitful discussions of the work and assistance for scientific publications. We are also thankful to the Multi-Access Center "Bioinformatics" for the use of computational resources as supported by Russian government project \#0259-2021-0009. We are appreciative of the Center for Genomic Research at the ICG SB RAS, where RNA-Seq was carried out.

Conflicts of Interest: The authors declare no conflict of interest. 


\section{References}

1. Belyaev, D.K. Destabilizing selection as a factor in domestication. J. Hered. 1979, 70, 301-308. [CrossRef]

2. Belyaev, D.K.; Evsikov, V.; Matysko, E.K. Genetics of animal fertility. 3. Effect of monohybrid heterosis on fertility and viability of minks, and prospects of its use in breeding. Sov. Genet. 1972, 8, 46-51.

3. Belyaev, D.K.; Trut, L.N.; Ruvinsky, A.O. Genetics of the W Locus in Foxes and Expression of its Lethal Effects. J. Hered. 1975, 66, 331-338. [CrossRef]

4. Belyaev, D.K.; Gruntenko, E.V. Strain Differences in Thymus Weight in Mice with Different Predispositions to Spontaneous Mammary Cancer. Nature 1972, 237, 401-402. [CrossRef] [PubMed]

5. Osadchuk, A.V.; Markel', A.L.; Khusainov, R.; Naumenko, E.V.; Beliaev, D.K. Problems in the genetics of stress. IV. A genetic analysis of the level of autonomic reactivity in emotional stress in rats. Genetika 1979, 15, 1847-1857. [PubMed]

6. Ponomarenko, M.; Gunbin, K.; Doroshkov, A.; Kolchanov, N. Cladogenesis. In Brenner's Encyclopedia of Genetics, 2nd ed.; Maloy, S., Hughes, K., Eds.; Academic Press: San Diego, CA, USA, 2013; Volume 2, pp. 21-24.

7. Bray, E.E.; Otto, C.M.; Udell, M.A.R.; Hall, N.J.; Johnston, A.M.; MacLean, E.L. Enhancing the selection and performance of working dogs. Front. Vet. Sci. 2021, 8, 644431. [CrossRef]

8. Eason, C.T.; Adams, S.L.; Puddick, J.; Romanazzi, D.; Miller, M.R.; King, N.; Johns, S.; Forbes-Blom, E.; Hessian, P.A.; Stamp, L.K.; et al. Greenshell ${ }^{\mathrm{TM}}$ Mussels: A Review of Veterinary Trials and Future Research Directions. Vet. Sci. 2018, 5, 36. [CrossRef] [PubMed]

9. Peng, J.; Tang, Y.; Huang, Y. Gut health: The results of microbial and mucosal immune interactions in pigs. Anim. Nutr. 2021, 7, 282-294. [CrossRef]

10. Ma, B.Y.; Gong, Q.L.; Sheng, C.Y.; Liu, Y.; Ge, G.Y.; Li, D.L.; Diao, N.C.; Shi, K.; Li, J.M.; Sun, Z.B.; et al. Prevalence of bovine leukemia in 1983-2019 in China: A systematic review and meta-analysis. Microb. Pathog. 2021, 150, 104681. [CrossRef]

11. Orlando, L. The Evolutionary and Historical Foundation of the Modern Horse: Lessons from Ancient Genomics. Annu. Rev. Genet. 2020, 54, 563-581. [CrossRef]

12. Thorne, J.W.; Murdoch, B.M.; Freking, B.A.; Redden, R.R.; Murphy, T.W.; Taylor, J.B.; Blackburn, H.D. Evolution of the sheep industry and genetic research in the United States: Opportunities for convergence in the twenty-first century. Anim. Genet. 2021, 52, 395-408. [CrossRef] [PubMed]

13. Pathak, P.; Nayak, V.K.; Sinha, R.; Ganaie, B.A. Review on small ruminant conservation status and prospects in India. Trop. Anim. Health Prod. 2020, 52, 2817-2827. [CrossRef] [PubMed]

14. Rajkumar, U.; Rao, S.V.R.; Raju, M.V.L.N.; Chatterjee, R.N. Backyard poultry farming for sustained production and enhanced nutritional and livelihood security with special reference to India: A review. Trop. Anim. Health Prod. 2021, 53, 1-13. [CrossRef] [PubMed]

15. Wei, R.; Han, C.; Deng, D.; Ye, F.; Gan, X.; Liu, H.; Li, L.; Xu, H.; Wei, S. Research progress into the physiological changes in metabolic pathways in waterfowl with hepatic steatosis. Br. Poult. Sci. 2020, 62, 118-124. [CrossRef]

16. Gao, G.; Gao, D.; Zhao, X.; Xu, S.; Zhang, K.; Wu, R.; Yin, C.; Li, J.; Xie, Y.; Hu, S.; et al. Genome-Wide Association Study-Based Identification of SNPs and Haplotypes Associated with Goose Reproductive Performance and Egg Quality. Front. Genet. 2021, 12, 602583. [CrossRef]

17. Courtier-Orgogozo, V.; Martin, A. The coding loci of evolution and domestication: Current knowledge and implications for bio-inspired genome editing. J. Exp. Biol. 2020, 223, jeb208934. [CrossRef]

18. Cowan, M.A.; Callan, M.N.; Watson, M.J.; Watson, D.M.; Doherty, T.S.; Michael, D.R.; Dunlop, J.A.; Turner, J.M.; Moore, H.A.; Watchorn, D.J.; et al. Artificial refuges for wildlife conservation: What is the state of the science? Biol. Rev. 2021. [CrossRef]

19. Belyaev, D.K.; Borodin, P.M. The influence of stress on variation and its role in evolution. Biol. Zent. 1982, 100, 705-714.

20. Plyusnina, I.; Oskina, I. Behavioral and Adrenocortical Responses to Open-Field Test in Rats Selected for Reduced Aggressiveness Toward Humans. Physiol. Behav. 1997, 61, 381-385. [CrossRef]

21. McGonigle, P.; Ruggeri, B. Animal models of human disease: Challenges in enabling translation. Biochem. Pharmacol. 2014, 87, 162-171. [CrossRef]

22. Lutz, C.; Maher, L.; Lee, C.; Kang, W. COVID-19 preclinical models: Human angiotensin-converting enzyme 2 transgenic mice. Hum. Genom. 2020, 14, 1-11. [CrossRef]

23. Hekman, J.P.; Johnson, J.; Edwards, W.; Vladimirova, A.V.; Gulevich, R.G.; Ford, A.L.; Kharlamova, A.V.; Herbeck, Y.; Acland, G.M.; Raetzman, L.T.; et al. Anterior Pituitary Transcriptome Suggests Differences in ACTH Release in Tame and Aggressive Foxes. G3 Genes Genomes Genet. 2018, 8, 859-873. [CrossRef]

24. Yang, X.; Zhang, H.; Shang, J.; Liu, G.; Xia, T.; Zhao, C.; Sun, G.; Dou, H. Comparative analysis of the blood transcriptomes between wolves and dogs. Anim. Genet. 2018, 49, 291-302. [CrossRef]

25. Albert, F.W.; Somel, M.; Carneiro, M.; Aximu-Petri, A.; Halbwax, M.; Thalmann, O.; Blanco-Aguiar, J.; Plyusnina, I.Z.; Trut, L.; Villafuerte, R.; et al. A Comparison of Brain Gene Expression Levels in Domesticated and Wild Animals. PLoS Genet. 2012, 8 , e1002962. [CrossRef] [PubMed]

26. Long, K.; Mao, K.; Che, T.; Zhang, J.; Qiu, W.; Wang, Y.; Tang, Q.; Ma, J.; Li, M.; Li, X. Transcriptome differences in frontal cortex between wild boar and domesticated pig. Anim. Sci. J. 2018, 89, 848-857. [CrossRef]

27. Yang, Y.; Adeola, A.C.; Xie, H.B.; Zhang, Y.P. Genomic and transcriptomic analyses reveal selection of genes for puberty in Bama Xiang pigs. Zool. Res. 2018, 39, 424-430. [CrossRef] 
28. Sato, D.X.; Rafati, N.; Ring, H.; Younis, S.; Feng, C.; Blanco-Aguiar, J.A.; Rubin, C.-J.; Villafuerte, R.; Hallböök, F.; Carneiro, M.; et al. Brain Transcriptomics of Wild and Domestic Rabbits Suggests That Changes in Dopamine Signaling and Ciliary Function Contributed to Evolution of Tameness. Genome Biol. Evol. 2020, 12, 1918-1928. [CrossRef] [PubMed]

29. Fallahshahroudi, A.; Lotvedt, P.; Belteky, J.; Altimiras, J.; Jensen, P. Changes in pituitary gene expression may underlie multiple domesticated traits in chickens. Heredity 2019, 122, 195-204. [CrossRef] [PubMed]

30. Theofanopoulou, C.; Gastaldon, S.; O’Rourke, T.; Samuels, B.D.; Messner, A.; Martins, P.T.; Delogu, F.; Alamri, S.; Boeckx, C. Self-domestication in Homo sapiens: Insights from comparative genomics. PLoS ONE 2017, 12, e0185306. [CrossRef]

31. Del Savio, L.; Mameli, M. Human domestication and the roles of human agency in human evolution. Hist. Philos. Life Sci. 2020, 42, 21. [CrossRef]

32. Gunbin, K.; Ponomarenko, M.P.; Suslov, V.V.; Gusev, F.; Fedonin, G.G.; Rogaev, E.I. Evolution of Brain Active Gene Promoters in Human Lineage Towards the Increased Plasticity of Gene Regulation. Mol. Neurobiol. 2017, 55, 1871-1904. [CrossRef]

33. Chadaeva, I.; Ponomarenko, P.; Rasskazov, D.; Sharypova, E.; Kashina, E.; Kleshchev, M.; Ponomarenko, M.; Naumenko, V.; Savinkova, L.; Kolchanov, N.; et al. Natural Selection Equally Supports the Human Tendencies in Subordination and Domination: A Genome-Wide Study With in silico Confirmation and in vivo Validation in Mice. Front. Genet. 2019, 10, 73. [CrossRef] [PubMed]

34. Oshchepkov, D.; Ponomarenko, M.; Klimova, N.; Chadaeva, I.; Bragin, A.; Sharypova, E.; Shikhevich, S.; Kozhemyakina, R. A Rat Model of Human Behavior Provides Evidence of Natural Selection against Underexpression of Aggressiveness-Related Genes in Humans. Front. Genet. 2019, 10, 1267. [CrossRef]

35. Tenenhaus, M.; Tenenhaus, A.; Groenen, P.J.F. Regularized Generalized Canonical Correlation Analysis: A Framework for Sequential Multiblock Component Methods. Psychometrika 2017, 82, 737-777. [CrossRef]

36. Klimova, N.V.; Chadaeva, I.V.; Shichevich, S.G.; Kozhemyakina, R.V. Differential expression of 10 genes in the hypothalamus of two generations of rats selected for a reaction to humans. Vavilovskii Zhurnal Genet. Sel. 2021, 25, $208-215$.

37. Naumenko, E.; Popova, N.; Nikulina, E.; Dygalo, N.; Shishkina, G.; Borodin, P.; Markel, A. Behavior, adrenocortical activity, and brain monoamines in Norway rats selected for reduced aggressiveness towards man. Pharmacol. Biochem. Behav. 1989, 33, 85-91. [CrossRef]

38. Paxinos, G.; Watson, C.R. The Rat Brain in Stereotaxic Coordinates, 7th ed.; Academic Press: London, UK, 2013 ; p. 472.

39. Walker, S.E.; Papilloud, A.; Huzard, D.; Sandi, C. The link between aberrant hypothalamic-pituitary-adrenal axis activity during development and the emergence of aggression-Animal studies. Neurosci. Biobehav. Rev. 2018, 91, 138-152. [CrossRef] [PubMed]

40. Sayers, E.W.; Beck, J.; Bolton, E.; Bourexis, D.; Brister, J.R.; Canese, K.; Comeau, D.C.; Funk, K.; Kim, S.; Klimke, W.; et al. Database resources of the National Center for Biotechnology Information. Nucleic Acids Res. 2020, 49, D10-D17. [CrossRef]

41. Bolger, A.M.; Lohse, M.; Usadel, B. Trimmomatic: A flexible trimmer for Illumina sequence data. Bioinformatics 2014, 30, 2114-2120. [CrossRef]

42. Kim, D.; Pertea, G.; Trapnell, C.; Pimentel, H.; Kelley, R.; Salzberg, S.L. TopHat2: Accurate alignment of transcriptomes in the presence of insertions, deletions and gene fusions. Genome Biol. 2013, 14, 36. [CrossRef] [PubMed]

43. Li, H.; Handsaker, B.; Wysoker, A.; Fennell, T.; Ruan, J.; Homer, N.; Marth, G.; Abecasis, G.; Durbin, R. The Sequence alignment/map (SAM) format and SAMtools. Bioinformatics 2009, 25, 2078-2079. [CrossRef]

44. Anders, S.; Pyl, P.T.; Huber, W. HTSeq-A Python framework to work with high-throughput sequencing data. Bioinformatics 2015, 31, 166-169. [CrossRef]

45. Love, M.I.; Huber, W.; Anders, S. Moderated estimation of fold change and dispersion for RNA-seq data with DESeq2. Genome Biol. 2014, 15, 550. [CrossRef] [PubMed]

46. Anders, S.; Huber, W. Differential expression analysis for sequence count data. Genome Biol. 2010, 11, 106. [CrossRef] [PubMed]

47. Ye, J.; Coulouris, G.; Zaretskaya, I.; Cutcutache, I.; Rozen, S.; Madden, T.L. Primer-BLAST: A tool to design target-specific primers for polymerase chain reaction. BMC Bioinform. 2012, 13, 134. [CrossRef] [PubMed]

48. Tian, L.; Chen, Y.; Wang, D.W.; Liu, X.H. Validation of reference genes via qRT-PCR in multiple conditions in brandt's voles, lasiopodomys brandtii. Animals 2021, 11, 897. [CrossRef] [PubMed]

49. Zamani, A.; Powell, K.L.; May, A.; Semple, B.D. Validation of reference genes for gene expression analysis following experimental traumatic brain injury in a pediatric mouse model. Brain Res. Bull. 2020, 156, 43-49. [CrossRef]

50. Gholami, K.; Loh, S.Y.; Salleh, N.; Lam, S.K.; Hoe, S.Z. Selection of suitable endogenous reference genes for qPCR in kidney and hypothalamus of rats under testosterone influence. PLoS ONE 2017, 12, e0176368. [CrossRef]

51. Penning, L.C.; Vrieling, H.E.; Brinkhof, B.; Riemers, F.M.; Rothuizen, J.; Rutteman, G.R.; Hazewinkel, H.A. A validation of 10 feline reference genes for gene expression measurements in snap-frozen tissues. Vet. Immunol. Immunopathol. 2007, 120, $212-222$. [CrossRef]

52. Lu, Z. PubMed and beyond: A survey of web tools for searching biomedical literature. Database 2011, 2011, baq036. [CrossRef]

53. Chapman, R.N. Animal ecology, with special reference to insects. J. Nerv. Ment. Dis. 1933, 78, 680. [CrossRef]

54. Pianka, E.R. Natural Selection of Optimal Reproductive Tactics. Am. Zool. 1976, 16, 775-784. [CrossRef]

55. Chadaeva, I.; Ponomarenko, P.M.; Rasskazov, D.A.; Sharypova, E.B.; Kashina, E.V.; Zhechev, D.A.; Drachkova, I.A.; Arkova, O.V.; Savinkova, L.K.; Ponomarenko, M.P.; et al. Candidate SNP markers of reproductive potential are predicted by a significant change in the affinity of TATA-binding protein for human gene promoters. BMC Genom. 2018, 19. [CrossRef] 
56. Ponomarenko, M.; Kleshchev, M.; Ponomarenko, P.; Chadaeva, I.; Sharypova, E.; Rasskazov, D.; Kolmykov, S.; Drachkova, I.; Vasiliev, G.; Gutorova, N.; et al. Disruptive natural selection by male reproductive potential prevents underexpression of protein-coding genes on the human Y chromosome as a self-domestication syndrome. BMC Genet. 2020, 21, 89. [CrossRef] [PubMed]

57. Vasiliev, G.; Chadaeva, I.; Rasskazov, D.; Ponomarenko, P.; Sharypova, E.; Drachkova, I.; Bogomolov, A.; Savinkova, L.; Ponomarenko, M.; Kolchanov, N.; et al. A Bioinformatics Model of Human Diseases on the Basis of Differentially Expressed Genes (of Domestic Versus Wild Animals) That Are Orthologs of Human Genes Associated with Reproductive-Potential Changes. Int. J. Mol. Sci. 2021, 22, 2346. [CrossRef]

58. Klimova, N.V.; Oshchepkova, E.; Chadaeva, I.; Sharypova, E.; Ponomarenko, P.; Drachkova, I.; Rasskazov, D.; Oshchepkov, D.; Ponomarenko, M.; Savinkova, L.; et al. Disruptive Selection of Human Immunostimulatory and Immunosuppressive Genes Both Provokes and Prevents Rheumatoid Arthritis, Respectively, as a Self-Domestication Syndrome. Front. Genet. 2021, $12,610774$. [CrossRef] [PubMed]

59. Samet, H. A top-down quadtree traversal algorithm. IEEE Trans. Pattern Anal. Mach. Intell. 1985, 7, 94-98. [CrossRef]

60. Sun, G.-L.; Shen, W.; Wen, J.-F. Triosephosphate Isomerase Genes in Two Trophic Modes of Euglenoids (Euglenophyceae) and Their Phylogenetic Analysis. J. Eukaryot. Microbiol. 2008, 55, 170-177. [CrossRef]

61. Morozova, O.V.; Alekseeva, A.E.; Sashina, T.A.; Brusnigina, N.F.; Epifanova, N.V.; Kashnikov, A.U.; Zverev, V.V.; Novikova, N.A. Phylodynamics of G4P[8] and G2P[4] strains of rotavirus A isolated in Russia in 2017 based on full-genome analyses. Virus Genes 2020, 56, 537-545. [CrossRef] [PubMed]

62. Hakizimana, J.N.; Yona, C.; Kamana, O.; Nauwynck, H.; Misinzo, G. African Swine Fever Virus Circulation between Tanzania and Neighboring Countries: A Systematic Review and Meta-Analysis. Viruses 2021, 13, 306. [CrossRef] [PubMed]

63. Zhang, Y.; Katoh, T.K.; Finet, C.; Izumitani, H.F.; Toda, M.J.; Watabe, H.-A.; Katoh, T. Phylogeny and evolution of mycophagy in the Zygothrica genus group (Diptera: Drosophilidae). Mol. Phylogenet. Evol. 2021, 163, 107257. [CrossRef] [PubMed]

64. Namazi, M.R. Minor thalassemia may be a risk factor for impulsiveness. Med. Hypotheses 2003, 60, 335-336. [CrossRef]

65. Takhviji, V.; Zibara, K.; Azarkeivan, A.; Mehrvar, N.; Mehrvar, N.; Mezginejad, F.; Khosravi, A. Fertility and pregnancy in Iranian thalassemia patients: An update on transfusion complications. Transfus. Med. 2020, 30, 352-360. [CrossRef] [PubMed]

66. Elalfy, M.S.; Ibrahim, A.S.; Ibrahim, G.S.; Hussein, H.M.A.G.; Mohammed, H.G.E.; Ebeid, F.S.E. Hidden brain iron content in sickle cell disease: Impact on neurocognitive functions. Eur. J. Nucl. Med. Mol. Imaging 2021, 180, 2677-2686. [CrossRef]

67. Moffitt, T.; Brammer, G.L.; Caspi, A.; Fawcett, J.; Raleigh, M.; Yuwiler, A.; Silva, P. Whole Blood Serotonin Relates to Violence in an Epidemiological Study. Biol. Psychiatry 1998, 43, 446-457. [CrossRef]

68. Mørkholt, A.S.; Wiborg, O.; Nieland, J.G.K.; Nielsen, S.; Nieland, J.D. Blocking of carnitine palmitoyl transferase 1 potently reduces stress-induced depression in rat highlighting a pivotal role of lipid metabolism. Sci. Rep. 2017, 7, 2158. [CrossRef]

69. Zapata, I.; Serpell, J.A.; Alvarez, C.E. Genetic mapping of canine fear and aggression. BMC Genom. 2016, 17, 572. [CrossRef]

70. Coulon, M.; Lévy, F.; Ravel, C.; Nowak, R.; Boissy, A. Mild effects of gestational stress and social reactivity on the onset of mother-young interactions and bonding in sheep. Stress 2014, 17, 460-470. [CrossRef] [PubMed]

71. Kaiser, S.; Hennessy, M.; Sachser, N. Domestication affects the structure, development and stability of biobehavioural profiles. Front. Zool. 2015, 12, S19. [CrossRef] [PubMed]

72. Tiric-Campara, M.; Tupkovic, E.; Mazalovic, E.; Karalic, E.; Biscevic, M.; Djelilovic-Vranic, J.; Alajbegovic, A. Correlation of aggressiveness and anxiety in fighting sports. Med. Arch. 2012, 66, 116-121. [CrossRef]

73. Stroop, J.R. Studies of interference in serial verbal reactions. J. Exp. Psychol. 1935, 18, 643-662. [CrossRef]

74. Keinan, G.; Friedland, N.; Kahneman, D.; Roth, D. The effect of stress on the suppression of erroneous competing responses. Anxiety Stress. Coping 1999, 12, 455-476. [CrossRef]

75. Smith, J.R.; Hayman, G.T.; Wang, S.-J.; Laulederkind, S.J.F.; Hoffman, M.J.; Kaldunski, M.L.; Tutaj, M.; Thota, J.; Nalabolu, H.S.; Ellanki, S.L.R.; et al. The Year of the Rat: The Rat Genome Database at 20: A multi-species knowledgebase and analysis platform. Nucleic Acids Res. 2019, 48, D731-D742. [CrossRef] [PubMed]

76. Hauser, A.; Troesch, S.; Steiner, T.; Brocherie, F.; Girard, O.; Saugy, J.J.; Schmitt, L.; Millet, G.P.; Wehrlin, J.P. Do male athletes with already high initial haemoglobin mass benefit from 'live high-train low' altitude training? Exp. Physiol. 2018, 103, 68-76. [CrossRef]

77. Büdefeld, T.; Tobet, S.A.; Majdic, G. Steroidogenic Factor 1 and the Central Nervous System. J. Neuroendocrinol. 2011, 24, 225-235. [CrossRef] [PubMed]

78. Domenice, S.; Machado, A.Z.; Ferreira, F.M.; Ferraz-de-Souza, B.; Lerario, A.M.; Lin, L.; Nishi, M.Y.; Gomes, N.L.; da Silva, T.E.; Silva, R.B.; et al. Wide spectrum of NR5A1-related phenotypes in 46,XY and 46,XX individuals. Birth Defects Res. Part C Embryo Today 2016, 108, 309-320.

79. Fu, Y.-X.; Ji, J.; Shan, F.; Li, J.; Hu, R. Human mesenchymal stem cell treatment of premature ovarian failure: New challenges and opportunities. Stem Cell Res. Ther. 2021, 12, 161. [CrossRef] [PubMed]

80. Yilmaz, B.D.; Bulun, S. Endometriosis and nuclear receptors. Hum. Reprod. Updat. 2019, 25, 473-485. [CrossRef] [PubMed]

81. Bösch, F.; Angele, M.K.; Chaudry, I.H. Gender differences in trauma, shock and sepsis. Mil. Med. Res. 2018, 5, 35. [CrossRef]

82. Kumar, R.; Thompson, E. The structure of the nuclear hormone receptors. Steroids 1999, 64, 310-319. [CrossRef] 
83. Hoffmann, S.; Roeth, R.; Diebold, S.; Gogel, J.; Hassel, D.; Just, S.; Rappold, G.A. Identification and Tissue-Specific Characterization of Novel SHOX-Regulated Genes in Zebrafish Highlights SOX Family Members Among Other Genes. Front. Genet. 2021, 12, 688808. [CrossRef] [PubMed]

84. German, A.; Mesch, G.; Hochberg, Z. People Are Taller in Countries with Better Environmental Conditions. Front. Endocrinol. 2020, 11, 106. [CrossRef]

85. Upners, E.N.; Jensen, R.B.; Meyts, E.R.; Dunø, M.; Aksglaede, L.; Juul, A. Short stature homeobox-containing gene duplications in $3.7 \%$ of girls with tall stature and normal karyotypes. Acta Paediatr. 2017, 106, 1651-1657. [CrossRef] [PubMed]

86. Magann, E.F.; Winchester, M.I.; Carter, D.P.; Martin, J.N.; Bass, J.D.; Morrison, J.C. Factors Adversely Affecting Pregnancy Outcome in the Military. Am. J. Perinatol. 1995, 12, 462-466. [CrossRef] [PubMed]

87. Rosin, J.M.; Abassah-Oppong, S.; Cobb, J. Comparative transgenic analysis of enhancers from the human SHOX and mouse Shox2 genomic regions. Hum. Mol. Genet. 2013, 22, 3063-3076. [CrossRef] [PubMed] 